Archive for

Organic Chemistry

Arkivoc 2017, part iv, 20-33

\title{
Attempts towards the synthesis of mupirocin-H
}

\author{
Shobanbabu Bommagani, ${ }^{\text {a, }}$ b Prashanth Thodupunuri, ${ }^{a}$ and \\ Gangavaram V. M. Sharma ${ }^{a}$
}

${ }^{a}$ Organic and Bimolecular Chemistry Division, CSIR-Indian Institute of Chemical Technology, Hyderabad 500 007, India

${ }^{b}$ College of pharmacy, Department of Pharmaceutical sciences, University of Arkansas for Medical Sciences, Little Rock,

AR 72212, USA

E-mail:sbommagani@uams.edu; shobaniict@gmail.com

Received 06-18-2016

Accepted 04-16-2017

Published on line 04-29-2017

\section{Abstract}

The stereoselective synthesis of segments C1-C6 (3), C7-C12 (4) of mupirocin-H has been achieved. The synthetic procedure for the C1-C6 segment includes the zinc mediated allyl Grignard reaction with $R$ glyceraldehyde, Swern oxidation/Witting olefination reactions and followed by Sharpless asymmetric epoxidation. The C7-C12 segment was synthesized using again Sharpless asymmetric epoxidation on mono PMB protected 2-butene-1,4-diol, followed by regioselective opening of this epoxide with trimethyl aluminium. Both segments C1-C6 (3) and C7-C12 (4) possesses the five new stereogenic centers along with trans-olefin, but in various attempts condensation of $\mathbf{3}$ and $\mathbf{4}$ segments to give C-C bond forming parent segment (2) not affirmed, hence this work constitutes the synthesis of fragments C1-C6 (3) and C7-C12 (4) of mupirocin-H.

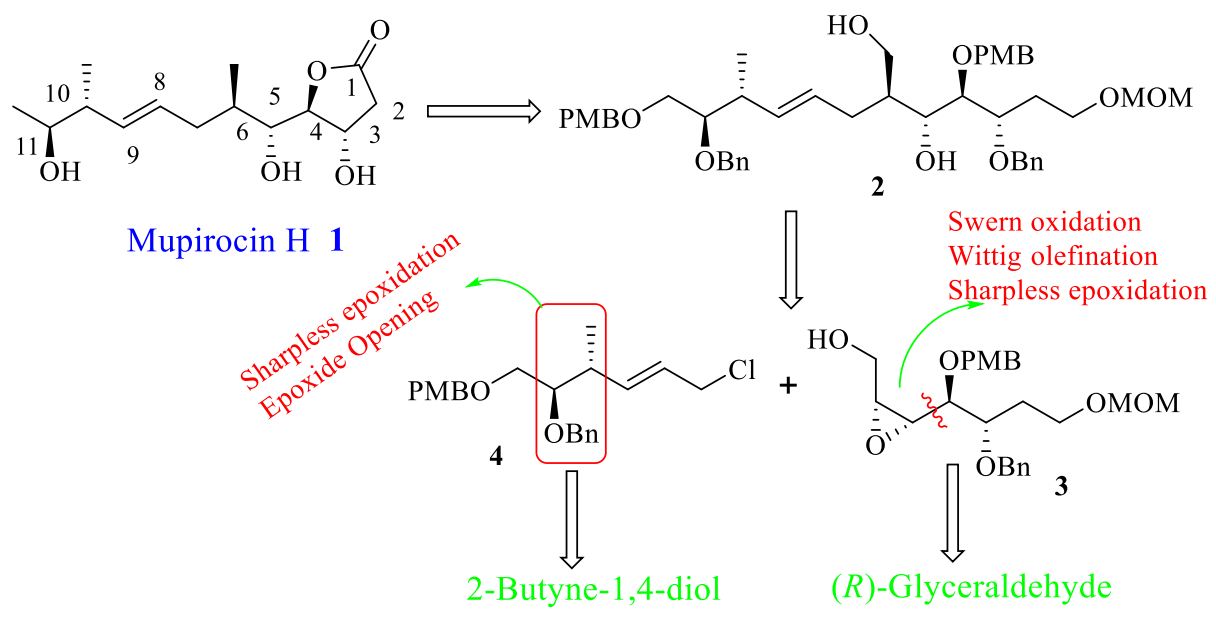

Keywords: Mupirocin-H, Sharpless asymmetric epoxidation, Wittig-olefination, D-mannitol 


\section{Introduction}

Mupirocin is a polyketide, found to be possess a wider spectrum of antibacterial activity against both grampositive, -negative bacteria, including methicillin-resistant staphylococcus aureus (MRSA) and it is used clinically for the treatment of bacterial skin infections. ${ }^{1}$ It is a mixture of pseudomonic acids produced by Pseudomonas fluorescens, a soil isolate reported to possess antibacterial activity as early as $1887,2,3$ while the mixture of pseudomonic acids was found to be the active component in the $1960 \mathrm{~s},{ }^{4}$ the major constituent was characterized later and named pseudomonic acid A (mupirocin). ${ }^{5,6} \mathrm{It}$ is prescribed for treating skin infections such as cuts, burn wounds, candidiasis and impetigo. Besides mupirocin inhibits the bacterial isoleucyl tRNA synthetase enzyme responsible for loading the amino acid isoleucine onto its cognate tRNA required for ribosomal protein synthesis. Aminoacyl tRNA synthetases belong to a super family of nucleotidyl transferase enzymes related to other ATP-binding proteins such as dehydrogenases and photolyase. ${ }^{7,8}$ Consequently, mupirocin- $\mathrm{H}$ 1, is a novel metabolite belongs to the family of mupirocin and it is resulted mutation of the $\beta$ hydroxy- $\beta$-methylglutaryl coenzyme A (HMG-CoA) synthase encoding mup $H$ gene in Pseudomonas fluorescens and providing in vivo evidence for the roles of mup $H$ and cognate genes found in several "AT-less" and other bacterial PKS gene clusters responsible for the biosynthesis of diverse metabolites containing acetate/propionate derived side chains, as well as possess anti bacterial activity akin mupirocin. 3,9,10 Moreover, Mupirocin-H consisting of six stereogenic centers and one trans-olefinic bond, the structure of mupirocin-H was determined by extensive analysis spectroscopic data and has been confirmed by recent total syntheses. ${ }^{10-15}$

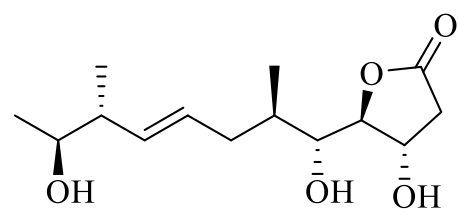

mupirocin $\mathrm{H} 1$

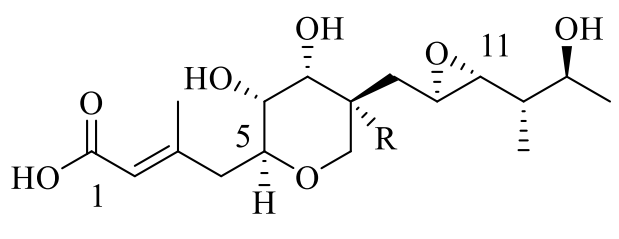

monic acid 1 a<smiles>[R][C@]1(C[C@H](O)[C@@H](C)[C@H](C)O)CO[C@H](C/C(C)=C/C(=O)OCCCCCCCCC(=O)O)[C@H](O)[C@@H]1O</smiles>

mupirocin (pseudomonic acid A, bactroban) $\mathbf{1 b}$ pseudomonic acid C (C10 - C11 is $E$-alkene) 1c

Figure 1. Structure of mupirocin and monic acids.

The amenable biological importance and fascinating structure of the mupirocin- $\mathrm{H}$ attracted the attention of chemists for the total synthesis. To date, five total synthesis of mupirocin- $\mathrm{H}$ were reported, sequentially are in 2011, the Chakraborty group reported the first enantioselective total synthesis of mupirocin- $\mathrm{H}$ in 19 steps with $5 \%$ overall yield by utilising D-glucose as the chiral source and Julia-Kocienski reaction for construction of the E-olefinic bond. ${ }^{12}$ In 2012 the Willis group also reported a convergent total synthesis of mupirocin $\mathrm{H}$ in 11 steps with 6.9\% overall yield using a functionalized lactone transformation strategy. ${ }^{10}$ In 2014 , She et al. have reported the total synthesis in 7 steps with $39 \%$ overall yield by utilizing Suzuki-Miyaura coupling reaction as 
key step. ${ }^{14}$ Again in 2014, T. Sim and co-worker reported the consise synthesis of mupirocin-H in 17 steps with $10.1 \%$ overall yield by using Grubbs reaction as key step. ${ }^{15}$

In present work our goal is to target the synthesis of mupirocin- $\mathrm{H}$. In a convergent synthesis, the target molecule mupirocin $\mathrm{H} 1$ was devided into two fragments C1-C6 (3) and C-7-C12 (4). Both the fragments are synthesized from commericially available starting materials. The detailed retro synthetic approach for the synthesis of mupirocin-H is depicted in scheme 1.

\section{Results and Discussion}

The retro synthetic analysis revealed that the target compound $\mathbf{1}$ (Scheme 1) could be obtained from alcohol 2, which on further conversion of resulting primary alcohol to methyl/C5-hydroxy protection/selective deprotection MOM ether, followed by oxidation to carboxylic acid and subsequent lactonization with deprotected C4-PMB ether. Compound $\mathbf{2}$ in turn could be obtained from two building blocks $\mathbf{3}$ and $\mathbf{4}$, while, epoxide 3 C-1 to C-6 segment could be obtained from $(R)$-glyceraldehyde derivative 5 (Scheme 2 \& 3). Similarly, 4 C-7 to C-12 segment could be derived from allyl alcohol 20, which was derived from commercially available 2-butyne-1,4- diol (Scheme 4 \& 5).

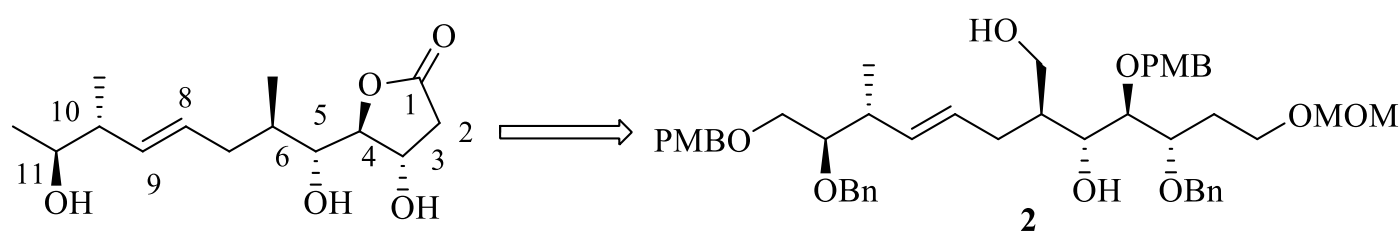

Mupirocin H 1

Sharpless epoxidation Epoxide Opening
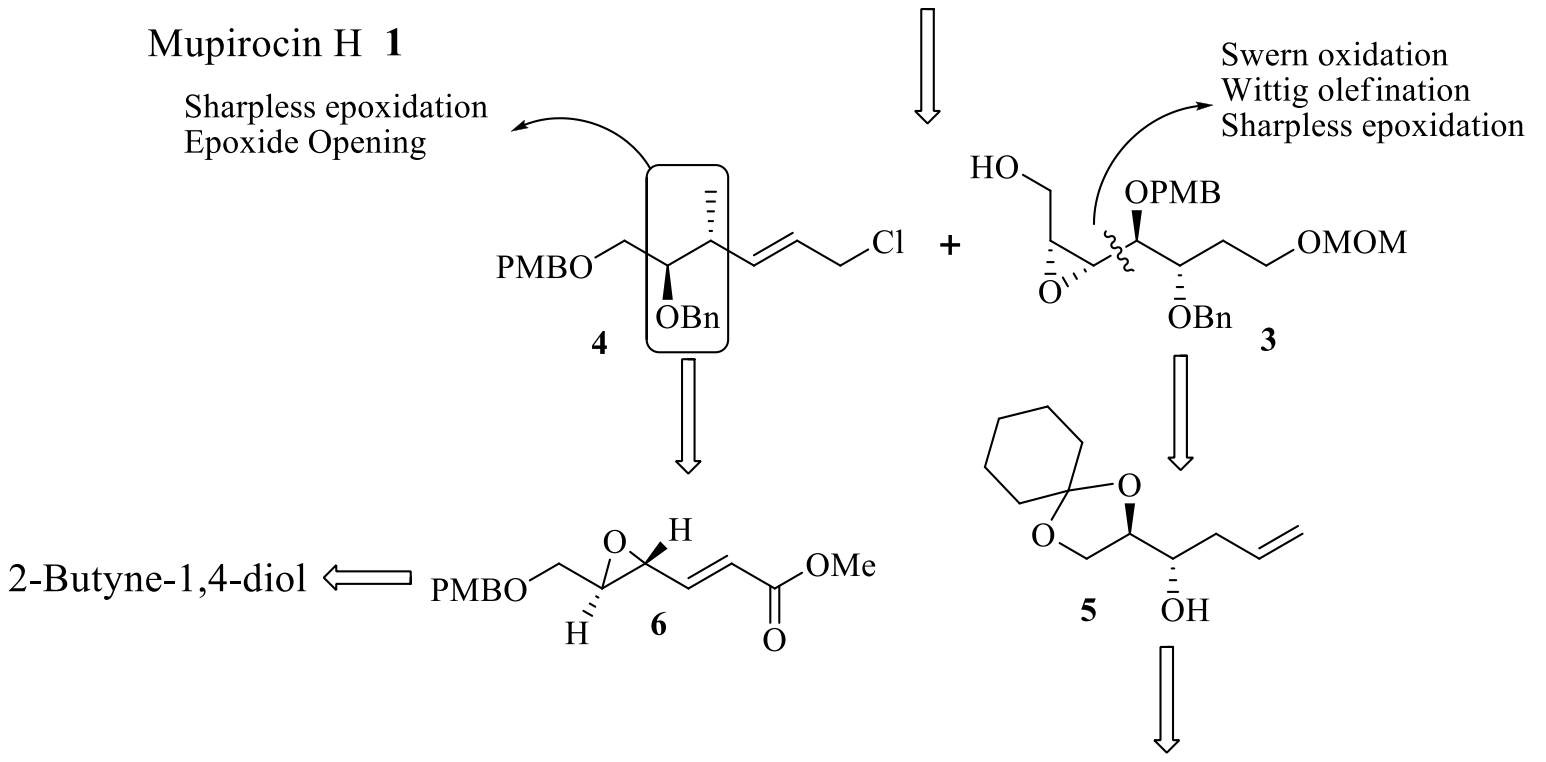

$(R)$-Glyceraldehyde

Scheme 1. Retro synthetic analysis of mupirocin-H.

Synthesis of C-1 to C-6 segment (3). Synthesis of fragment $\mathbf{3}$ is achieved as shown in Scheme 2. Allylation of $(R)$-Glyceraldehyde with allyl bromide in THF gave the isomeric mixture of compounds $\mathbf{5}$ and $\mathbf{5 a} .{ }^{16}$ The major isomer $\mathbf{5}$ isolated by colomn chromatography and further treated with benzyl bromide and NaH in THF to give 
the benzyl ether 7 in $94 \%$ yield. Then compound 7 was subjected to $70 \%$ aq. acetic acid at room temperature furnished diol 8 in $87 \%$ yield (Scheme 2). Diol 8 was selectively silylted using TBSCl and imidazole in dichloromethane at $0{ }^{\circ} \mathrm{C}$ to room temperature to give silyl ether 9 in $77 \%$ yield. Repeatedly, secondary alcohol in 9 was O-benzylated with $p$-methoxybenzyl bromide and $\mathrm{NaH}$ in THF to afford the PMB ether 10 in $91 \%$ yield. Dihydroxylation of terminal olefine of compound $\mathbf{1 0}$ in presence of $\mathrm{OsO}_{4}$ in acetone, water (9:1) using NMO as cooxidant gave diol 11 in 62\% yield. ${ }^{17}$ Then oxidative cleavage of diol 11 on reaction with $\mathrm{NaIO}_{4}$ and saturated $\mathrm{NaHCO}_{3}$ solution in $\mathrm{CH}_{2} \mathrm{Cl}_{2}$ furnished aldehyde 12, which on subsequent treatment with $\mathrm{NaBH}_{4}$ in $\mathrm{MeOH}$ at $0^{\circ} \mathrm{C}$ furnished alcohol 13 in $82 \%$ yield. Resulted alcohol 13 on reaction with $\mathrm{MOMCl}$ and DIPEA in $\mathrm{CH}_{2} \mathrm{Cl}_{2}$ at $0{ }^{\circ} \mathrm{C}$ afforded MOM ether 14 in $91 \%$ yield.

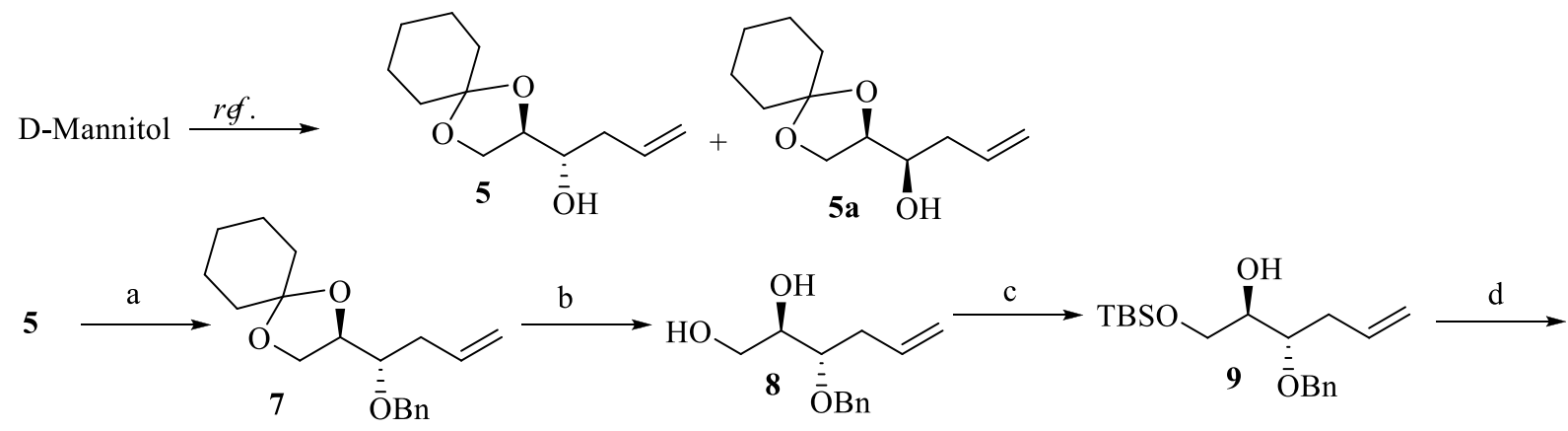

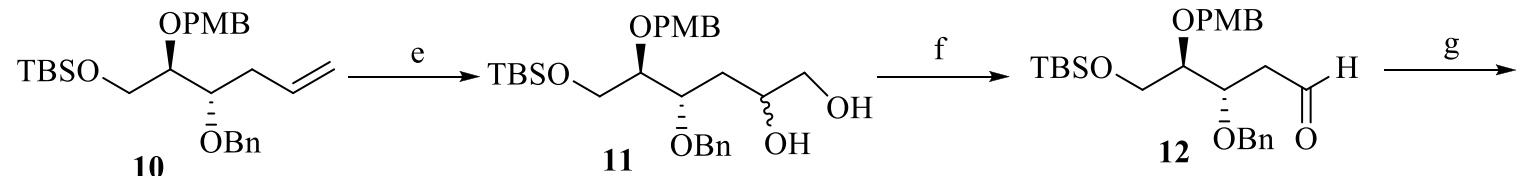

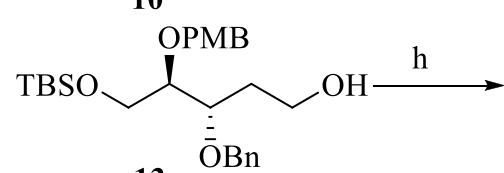
13<smiles></smiles>

OPMB<smiles>COC(=O)CO</smiles>

14<smiles>CCO[C@@H](CCOC)[C@H](C)O[Mg]</smiles>

Reagents and conditions: a) Bn-Br, NaH, THF, RT, 6 h; b) $70 \% \mathrm{AcOH}, \mathrm{RT}, 12 \mathrm{~h}$; c) TBS-Cl, Imidazole, $\mathrm{CH}_{2} \mathrm{Cl}_{2}$; d) PMB-Br, NaH, THF, RT, 6 h; e) $\mathrm{OsO}_{4}$, NMO, Acetone, $\mathrm{H}_{2} \mathrm{O}, 24 \mathrm{~h}$; f) $\mathrm{NaIO}_{4}$, sat. $\mathrm{NaHCO}_{3}, \mathrm{CH}_{2} \mathrm{Cl}_{2}$; g) $\mathrm{NaBH}_{4}, \mathrm{MeOH}_{\text {, }}$ $0{ }^{\circ} \mathrm{C}, 2 \mathrm{~h}$; h) MOM-Cl, DIPEA,DMAP, $\mathrm{CH}_{2} \mathrm{Cl}_{2}, 12 \mathrm{~h}$; i) TBAF, THF, $0{ }^{\circ} \mathrm{C}, 2 \mathrm{~h}$.

Scheme 2. Synthesis of intermediate 15 of C-1 to C-6 segment.

For the synthesis of one of the fragmet 3 from compound 14, first deprotected the TBS ether in compound 14 using TBAF in THF to give primary alcohol 15 in 85\% yields. The obtained alcohol 15 was subjected for Swern oxidation in $\mathrm{CH}_{2} \mathrm{Cl}_{2}$ at $-78{ }^{\circ} \mathrm{C}$ afforded aldehyde $16,{ }^{18,19}$ which on subsequent Wittig olefination with (ethoxycarbonylmethylene)triphenyl phosphorane in benzene gave mixture of $17 \mathrm{a}$ and $17 \mathrm{~b}$ in $1: 19$ ratio (75\%). ${ }^{20,21,22}$ Then using colomn chromatography technique purified major isomer $\mathbf{1 7 b}$ on selective reduction of ester with $\mathrm{LAH}$ and $\mathrm{AlCl}_{3}$ in ether at $0{ }^{\circ} \mathrm{C}$ furnished trans-allylic alcohol $\mathbf{1 8}$ in $78 \%$ yield (Scheme 3). The allylic alcohol 18 was subjected to enantioselective epoxidation under Sharpless asymmetric epoxidation reaction conditions using (+)-DIPT, $\mathrm{Ti}(i-\mathrm{OPr})_{4}$ and cumene hydroperoxide at $-20{ }^{\circ} \mathrm{C}$ furnished the desired chiral epoxide 3 in 70\% yield. ${ }^{23}$ 


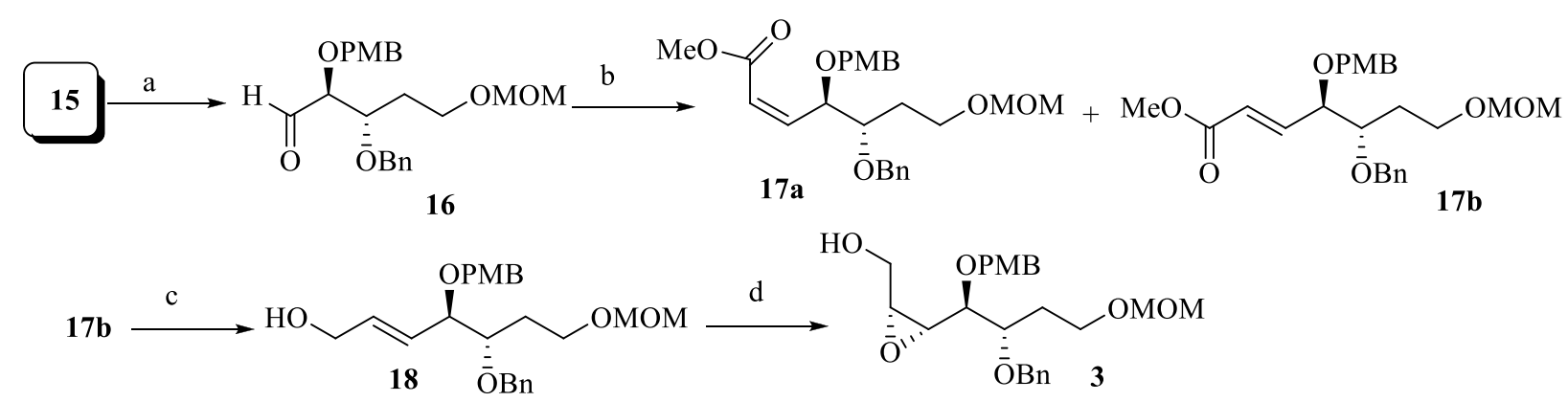

Reagents and conditions: a) $(\mathrm{COCl})_{2}$, DMSO, $\left.\mathrm{Et}_{3} \mathrm{~N}, \mathrm{CH}_{2} \mathrm{Cl}_{2},-78^{\circ} \mathrm{C}, 2 \mathrm{~h} ; \mathrm{b}\right)$ Benzene, $\left.\mathrm{Ph}_{3} \mathrm{P}=\mathrm{CHCOOMe}, 90{ }^{\circ} \mathrm{C}, 3 \mathrm{~h} ; \mathrm{c}\right)$ $\mathrm{LAH}, \mathrm{AlCl}_{3}$, Ether, $0{ }^{\circ} \mathrm{C}, 1 \mathrm{~h}$; d) (+)-DIPT, Ti(iPrO $)_{4}, \mathrm{CHP}, \mathrm{CH}_{2} \mathrm{Cl}_{2},-20{ }^{\circ} \mathrm{C}, 72 \mathrm{~h}$.

Scheme 3. Synthesis of C-1 to C-6 segment 3.

Synthesis of C-7 to C-12 segment (4). To acieve the synthesis of fragment 4 with required stereochemistry, we have used the commercially available achiral 2-butyn-1,4-diol as starting material as shown in Scheme 4. Accordingly, 2-butyne-1,4-diol was treated with PMB-Br, NaH and TBAI in THF to give PMB-ether 19, which on further reaction with Red-Al in dry ether afforded the trans-alcohol $\mathbf{2 0}$ in $62 \%$ yield. Alcohol $\mathbf{2 0}$ was subjected to enantio selective epoxidation under Sharpless epoxidation reaction conditions using (+)-DIPT, $\mathrm{Ti}(i-\mathrm{OPr})_{4}$ and cumene hydroperoxide at $-20{ }^{\circ} \mathrm{C}$ furnished the chiral epoxide 21 in $69 \%$ yield. ${ }^{23}$ The newly generated chiral epoxide alcohol $\mathbf{2 1}$ on oxidation under Swern reaction conditions ${ }^{18,19}$ gave aldehyde $\mathbf{2 2}$, which on subsequent Wittig olefination with (ethoxycarbonylmethylene)triphenyl phosphorane in benzene afforded 6 and 6a in 9:1 ratio (72\%). ${ }^{20,21,22}$ Epoxy ester 6 was treated with trimethylaluminium in $\mathrm{CH}_{2} \mathrm{Cl}_{2}$ at $-40{ }^{\circ} \mathrm{C}$ to give regioselective compound $\mathbf{2 3}$ in $85 \%$ yield an exclusively. ${ }^{24}$ Then, $\alpha, \beta$-unsaturated ester $\mathbf{2 3}$ on selective reduction of ester with $\mathrm{LAH}$ and $\mathrm{AlCl}_{3}$ in ether gave the diol $\mathbf{2 4}$ in 58\% yield. The primary alcohol in $\mathbf{2 4}$ was selectively silylated using TBSCl and imidazole in $\mathrm{CH}_{2} \mathrm{Cl}_{2}$ to give silyl ether 25 in $82 \%$ yield.
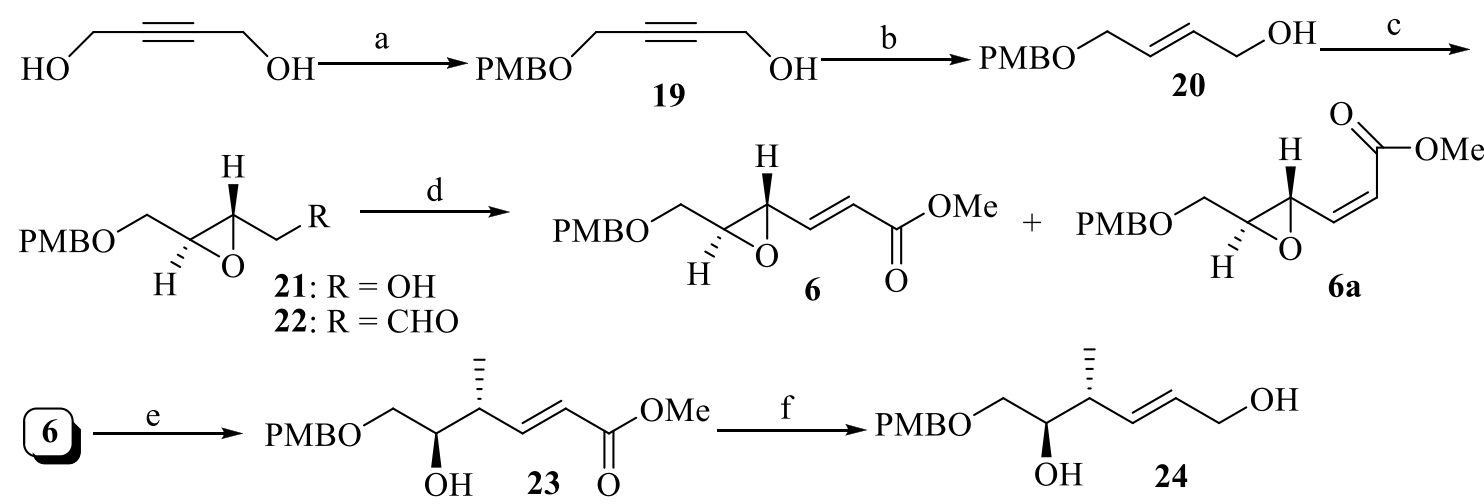

Reagents and Conditions: a) PMB-Br, NaH, TBAI ,THF, $12 \mathrm{~h}$; b) Red-Al, ether, $0{ }^{\circ} \mathrm{C}, 2 \mathrm{~h}$; c) (+) DIPT, Ti(O $\left(\mathrm{O}^{\mathrm{i}} \mathrm{Pr}\right)_{4}, \mathrm{CHP}$, $\mathrm{CH}_{2} \mathrm{Cl}_{2},-20{ }^{\circ} \mathrm{C}, 12 \mathrm{~h}$; d) (i) $(\mathrm{COCl})_{2}$, DMSO, $\mathrm{Et}_{3} \mathrm{~N}, \mathrm{CH}_{2} \mathrm{Cl}_{2},-78^{\circ} \mathrm{C}, 2 \mathrm{~h}$ (ii) Benzene, $\mathrm{Ph}_{3} \mathrm{P}=\mathrm{CHCOOMe}, 90^{\circ} \mathrm{C}, 3 \mathrm{~h}$; e) $\mathrm{Al}\left(\mathrm{CH}_{3}\right)_{3}, \mathrm{H}_{2} \mathrm{O}, \mathrm{CH}_{2} \mathrm{Cl}_{2},-40^{\circ} \mathrm{C}, 2 \mathrm{~h}$; f) $\mathrm{LAH}, \mathrm{AlCl}_{3}$, Ether, $0^{\circ} \mathrm{C}, 1 \mathrm{~h}$.

Scheme 4. Synthesis of intermediate 24 of C-7 to C-12 segment.

Confirmation of newly generated stereocenter in compound 23, first deprotection of PMB ether in compound 25, followed by protection of resulted diol 27 with 2,2-dimethoxy propane and PPTS (cat.) in $\mathrm{CH}_{2} \mathrm{Cl}_{2}$ afforded 28 in $73 \%$ yield. The stereochemistry of 26 was established by ${ }^{1} \mathrm{H} N M R\left(300 \mathrm{MHz} \mathrm{CDCl}_{3}\right)$ data of 
compound 28, which reveals that the adjacent vicinal proton coupling constants $(J=10.1 \mathrm{~Hz})$ of methyl and hydroxyl substituents are in anti-substitution pattern in $\mathbf{2 6 .}$

For taking the intermediate compound $\mathbf{2 5}$ to the target compound 4, first protection of secondary alcohol (25) with benzyl bromide and $\mathrm{NaH}$ in THF at room temperature afforded the benzyl ether $\mathbf{2 6}$ in $76 \%$ yield (Scheme 5). Finally, desylilation of $\mathbf{2 6}$ with TBAF in THF gave alcohol $\mathbf{2 9}$ in $\mathbf{8 8 \%}$ yield, which on reaction with triphenylphosphine, and $\mathrm{NaHCO}_{3}$ in $\mathrm{CCl}_{4}$ at $80{ }^{\circ} \mathrm{C}$ afforded allyl halide 4 in $90 \%$ yield.

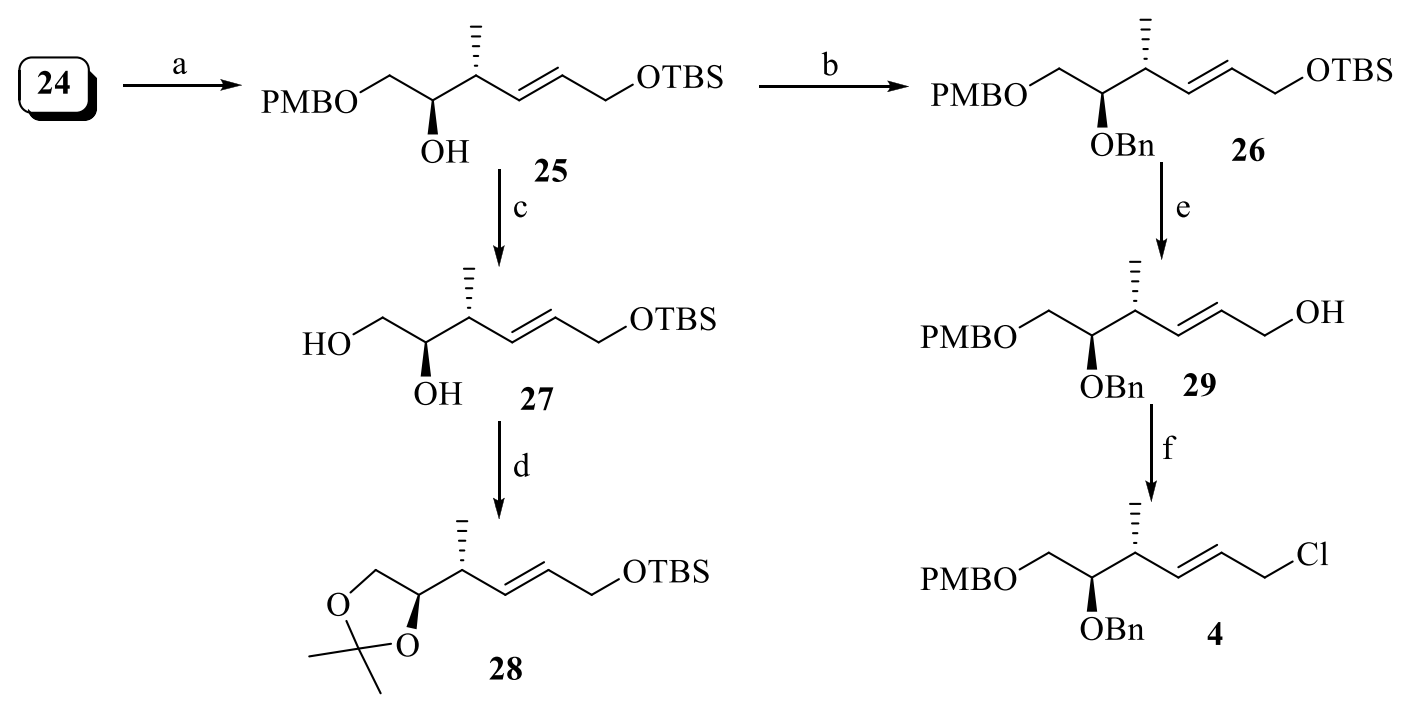

Reagents and Conditions: a) TBS-Cl, Imidazole, $\mathrm{CH}_{2} \mathrm{Cl}_{2}$; b) $\mathrm{Bn}-\mathrm{Br}, \mathrm{NaH}, \mathrm{THF}, 8 \mathrm{~h}$; c) DDQ, $\mathrm{CH}_{2} \mathrm{Cl}_{2}, \mathrm{H}_{2} \mathrm{O}(19: 1), 10 \mathrm{~min}$; d) 2,2-DMP, PPTS, $\mathrm{CH}_{2} \mathrm{Cl}_{2}, 2 \mathrm{~h}$; e) TBAF, THF, $2 \mathrm{~h}$; f) TPP, $\mathrm{CCl}_{4}, \mathrm{NaHCO}_{3}, 80{ }^{\circ} \mathrm{C}, 3 \mathrm{~h}$.

Scheme 5. Synthesis of C-7 to C-12 segment.

Attempts towards the synthesis of segment 2. In above obtained both segments C-1 to C-6, 3 (Scheme 3 ) and C-7 to C-12, 4 (Scheme 5) were further attempted to condense through epoxide opening procedure to furnish the main fragment 2 as shown in scheme 6. Hence the treatment of allyl halide $4 \mathrm{with} \mathrm{Mg}$ in ether at room temperature followed by reaction with 3 at $-78{ }^{\circ} \mathrm{C}$, few other attempts $-40{ }^{\circ} \mathrm{C},-20{ }^{\circ} \mathrm{C}$ and even at room temperature in dry ether/tetrahydrofuran reaction conditions were met with failure to furnish 2 (Scheme 6). 25,26

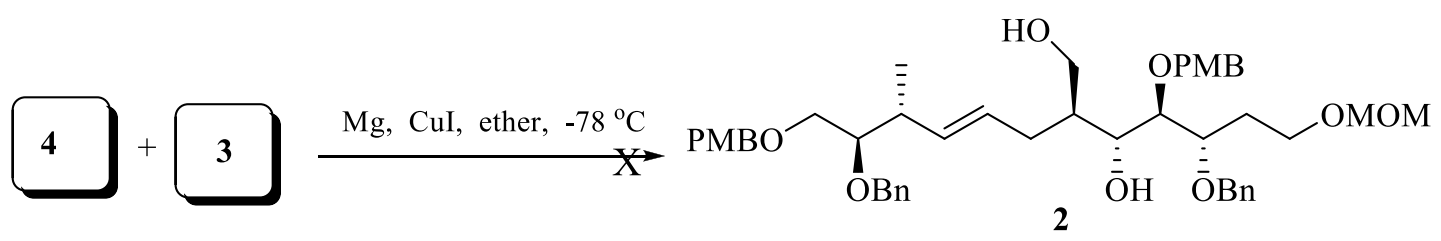

Scheme 6. Coupling of segments 3 and 4.

\section{Conclusions}


A route was developed for the synthesis of C1 to C6 (3), C7 to C12 (4) segments of mupirocin-H (1). In further attempts towards the synthesis of mupirocin-H 1 to form $\mathrm{C}-\mathrm{C}$ bond forming main segment (2) by using both segments C1-C6 (3) and C7-C12 (4) was not affirmed. So this is a synthetic protocol for the synthesis of C1 to C6 segment (3), which has three chiral centers, and C7 to C12 segment (4), which has two chiral centers along with trans-olefin. Further work on the synthesis of mupirocin $\mathrm{H}(\mathbf{1})$ is in progress in our laboratories, with modified protocols.

\section{Experimental Section}

General. Analytical thin layer chromatography (TLC) was carried out using silica gel 60 F254 pre-coated plates. Visualization was accomplished with UV lamp or $\mathrm{I}_{2}$ stain. All products were characterized by their NMR and HRMS spectra. The ${ }^{1} \mathrm{H}$ NMR (300 MHz) spectra were recorded on Bruker Avance spectrometer and ${ }^{13} \mathrm{C}$ NMR (75 MHz) spectra were recorded on Bruker Avance spectrometers using TMS as an internal standard, chemical shifts were reported in parts per million (ppm, $\delta$ ) downfield from tetramethylsilane. ESI, HRMS were recorded on 'High Resolution QSTAR XL hybrid MS/MS system, Applied biosystems' under Electron Spray Ionization conditions preparing sample solutions in $\mathrm{MeOH}$. IR spectra were recorded on Perkin-Elmer Infrared-683 spectrometer.

(1S)-1-[(2R)-1,4-Dioxaspiro[4.5]dec-2-yl]-3-buten-1-ol (5). To a cooled $\left(0^{\circ} \mathrm{C}\right)$ solution of mannitol diacetonide (20 g, $58.47 \mathrm{mmol})$ in $\mathrm{CH}_{2} \mathrm{Cl}_{2}(100 \mathrm{~mL}), \mathrm{NalO}_{4}(25.02 \mathrm{~g}, 116.95 \mathrm{mmol})$ followed by sat. $\mathrm{NaHCO}_{3}(8 \mathrm{~mL})$ were added and stirred at room temperature for $5 \mathrm{~h}$. Reaction mixture was dried $\left(\mathrm{Na}_{2} \mathrm{SO}_{4}\right)$, filtered and evaporated under reduced pressure to give $(R)$-Glyceraldehyde $(18 \mathrm{~g})$ and used as such to next reaction.

To a stirred and cooled $\left(0^{\circ} \mathrm{C}\right)$ mixture of $(R)$-Glyceraldehyde $(18 \mathrm{~g}, 105.26 \mathrm{mmol})$ and dry Zinc $(13.7 \mathrm{~g}, 210.50$ $\mathrm{mmol})$ in THF $(100 \mathrm{~mL})$, allyl bromide $(10.7 \mathrm{~mL}, 126.30 \mathrm{mmol})$ was added very slowly for $15 \mathrm{~min}$, followed by the addition of sat. $\mathrm{NH}_{4} \mathrm{Cl}(72 \mathrm{~mL})$ solution. After $6 \mathrm{~h}$, reaction mixture was diluted with excess sat. $\mathrm{NH}_{4} \mathrm{Cl}$ solution $(50 \mathrm{~mL})$ and extracted with ethyl acetate $(2 \times 100 \mathrm{~mL})$. The organic layers were washed with water $(2$ x $20 \mathrm{~mL})$, brine $(20 \mathrm{~mL})$, dried $\left(\mathrm{Na}_{2} \mathrm{SO}_{4}\right)$, evaporated under reduced pressure and purified the residue by column chromatography (Silica gel, 60-120 mesh, 5\% EtOAc in pet. ether) to furnish $\mathbf{5}$ (17.5 g, 78\%) as a yellow

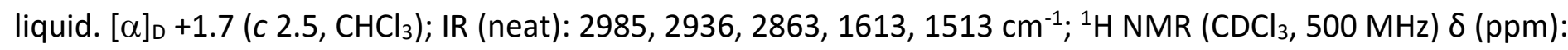
5.87-5.77 (m, 2H), 5.14-5.10 (m, 2H), 3.98-3.91 (m, 2H), 3.89-3.85 (m, 1H), 3.72-3.69 (m, 1H), 2.23-2.14 (m, $2 \mathrm{H}), 1.60-1.55(\mathrm{~m}, 8 \mathrm{H}), 1.41-1.38(\mathrm{~m}, 2 \mathrm{H})$; ESIMS: $235(\mathrm{M}+\mathrm{Na})^{+}, 213(\mathrm{M}+\mathrm{H})$.

(2R)-2-[(1S)-1-(Benzyloxy)-3-butenyl]-1,4-dioxaspiro[4.5]decane (7). To a cooled $\left(0{ }^{\circ} \mathrm{C}\right)$ solution of 5 (8.0 g, $54.8 \mathrm{mmol})$ in dry THF $(40 \mathrm{~mL}), \mathrm{NaH}(2.63 \mathrm{~g}, 109.6 \mathrm{mmol})$ was added, stirred for $30 \mathrm{~min}$ and treated with a solution of benzyl bromide $(12.05 \mathrm{~g}, 60.28 \mathrm{mmol})$. After stirring at room temperature for $6 \mathrm{~h}$, the reaction mixture was quenched with sat. $\mathrm{NH}_{4} \mathrm{Cl}$ solution $(8 \mathrm{~mL})$ and extracted with ethyl acetate $(2 \times 40 \mathrm{~mL})$. The organic layers were washed with water $(2 \times 10 \mathrm{~mL})$, brine $(10 \mathrm{~mL})$, dried $\left(\mathrm{Na}_{2} \mathrm{SO}_{4}\right)$, evaporated under reduced pressure and purified the residue by column chromatography (Silica gel, 60-120 mesh, 15\% EtOAc in pet. ether) to furnish 7 (12.1 g, 83\%) as a yellow liquid. $[\alpha]_{D}+41.7$ (c 1.5, $\left.\mathrm{CHCl}_{3}\right)$; IR (neat): 2985, 2936, 2863, 1613, $1513 \mathrm{~cm}^{-1} ;{ }^{1} \mathrm{H} \mathrm{NMR}\left(\mathrm{CDCl}_{3}, 300 \mathrm{MHz}\right) \delta(\mathrm{ppm}): 7.32-7.24(\mathrm{~m}, 5 \mathrm{H}),, 5.93-5.79(\mathrm{~m}, 1 \mathrm{H}), 5.14-5.04(\mathrm{~m}, 2 \mathrm{H}), 4.57(\mathrm{q}$, J $11.33 \mathrm{~Hz}, 2 \mathrm{H}), 4.02-3.95(\mathrm{~m}, 2 \mathrm{H}), 3.85-3.79(\mathrm{~m}, 1 \mathrm{H}), 3.52(\mathrm{q}, J 5.28 \mathrm{~Hz}, 1 \mathrm{H}), 2.46-2.27(\mathrm{~m}, 2 \mathrm{H}), 1.58-1.54(\mathrm{~m}$, $8 \mathrm{H}), 1.46-1.38(\mathrm{~s}, 2 \mathrm{H})$; ESIMS: $325(\mathrm{M}+\mathrm{Na})^{+}, 303(\mathrm{M}+\mathrm{H})$. 
(2R,3S)-3-(Benzyloxy)-5-hexene-1,2-diol (8). A solution of 7 (9.12 g, $0.03 \mathrm{mmol}$ ) in aq. $70 \%$ acetic acid (50 $\mathrm{mL})$ was stirred at room temperatature for $12 \mathrm{~h}$. After completion of reaction, it was quenched with $\mathrm{NaHCO}_{3}$ and adjusted to $\mathrm{pH}$ 2-3. The reaction mixture was extracted with ethyl acetate $(3 \times 100 \mathrm{~mL})$ and $\mathrm{dried}\left(\mathrm{Na}_{2} \mathrm{SO}_{4}\right)$. Evaporation of solvent under reduced pressure and purification of the residue by column chromatography (Silica gel, 60-120 mesh, 40\% EtOAc in pet. ether) afforded 8 (5.76 g, 86\%) as a yellow liquid. $[\alpha]_{\mathrm{D}}+42.9$ (c 1.0, $\mathrm{CHCl}_{3}$ ); IR (neat): 3456, 2990, 2942, 2863, 1613, $1513 \mathrm{~cm}^{-1} ;{ }^{1} \mathrm{H} \mathrm{NMR}\left(\mathrm{CDCl}_{3}, 300 \mathrm{MHz}\right) \delta$ (ppm): $7.32-7.24(\mathrm{~m}$, $5 \mathrm{H}), 5.93-5.79(\mathrm{~m}, 1 \mathrm{H}), 5.14-5.04(\mathrm{~m}, 2 \mathrm{H}), 4.57(\mathrm{q}, \mathrm{J} 11.33 \mathrm{~Hz}, 2 \mathrm{H}), 4.02-3.95(\mathrm{~m}, 2 \mathrm{H}), 3.85-3.79(\mathrm{~m}, 1 \mathrm{H}), 3.52(\mathrm{q}$, J $5.28 \mathrm{~Hz}, 1 \mathrm{H}), 2.46-2.27(\mathrm{~m}, 2 \mathrm{H}), 1.58-1.54(\mathrm{~m}, 8 \mathrm{H}), 1.46-1.38(\mathrm{~s}, 2 \mathrm{H})$; ESIMS: $245(\mathrm{M}+\mathrm{Na})^{+}, 223(\mathrm{M}+\mathrm{H})$.

(2R,3S)-3-(Benzyloxy)-1-[1-(tert.-butyl)-1,1-dimethylsilyl]oxy-5-hexen-2-ol (9). To a cooled $\left(0{ }^{\circ} \mathrm{C}\right)$ solution of 8 $(1.8 \mathrm{~g}, 8.10 \mathrm{mmol})$ in $\mathrm{CH}_{2} \mathrm{Cl}_{2}(30 \mathrm{~mL})$, imidazole $(1.10 \mathrm{~g}, 16.21 \mathrm{mmol})$ was added. After $30 \mathrm{~min} \mathrm{TBS}-\mathrm{Cl}(1.21 \mathrm{~g}$, $8.10 \mathrm{mmol}$ ) was added portion wise for $30 \mathrm{~min}$ and stirred at room temperature for $2 \mathrm{~h}$. The reaction mixture was evaporated and purified the residue by column chromatography (Silica gel, 60-120 mesh, 5\% EtOAc in pet. ether) to give 9 (2.08 g, 76.7\%) as a colorless liquid. [ $\alpha]_{D}+45.3$ (c 1.0, $\left.\mathrm{CHCl}_{3}\right)$; IR (neat): 3031, 2930, 2857, 1710, $1097 \mathrm{~cm}^{-1} ;{ }^{1} \mathrm{H}$ NMR $\left(\mathrm{CDCl}_{3}, 400 \mathrm{MHz}\right) \delta(\mathrm{ppm}):$ 7.32-7.25 (m, 5H), 5.95-5.81 (m, 1H), 5.15-5.04 (m, $\left.2 \mathrm{H}\right), 4.63(\mathrm{~d}$, J $12.08 \mathrm{~Hz}, 1 \mathrm{H}), 4.45(\mathrm{~d}, J 12.08 \mathrm{~Hz}, 1 \mathrm{H}), 3.71(\mathrm{t}, J 6.04 \mathrm{~Hz}, 1 \mathrm{H}), 3.65-3.58(\mathrm{~m}, 2 \mathrm{H}), 3.46(\mathrm{q}, J 6.04 \mathrm{~Hz}, 1 \mathrm{H}), 2.49$ $2.35(\mathrm{~m}, 2 \mathrm{H}), 0.89(\mathrm{~s}, 9 \mathrm{H}), 0.61(\mathrm{~s}, 6 \mathrm{H})$; ESIMS: $359(\mathrm{M}+\mathrm{Na})^{+}, 337(\mathrm{M}+\mathrm{H})$.

((2R,3S)-3-(Benzyloxy)-2-[(4-methoxybenzyl)oxy]-5-hexenyloxy)(tert-butyl) dimethylsilane (10). To a cooled $\left(0^{\circ} \mathrm{C}\right)$ solution of $9(5.93 \mathrm{~g}, 17.70 \mathrm{mmol})$ in dry THF $(30 \mathrm{~mL}), \mathrm{NaH}(1.22 \mathrm{~g}, 53.10 \mathrm{mmol})$ was added, stirred for 30 min and treated with a solution of $\operatorname{MPMBr}(4.22 \mathrm{~g}, 21.24 \mathrm{mmol})$ in dry THF $(15 \mathrm{~mL})$. After $6 \mathrm{~h}$ stirring at room temperature, the reaction mixture was quenched with sat. $\mathrm{NH}_{4} \mathrm{Cl}$ solution $(10 \mathrm{~mL})$ and extracted with ethyl acetate $(2 \times 50 \mathrm{~mL})$. The organic layers were washed with water $(2 \times 10 \mathrm{~mL})$, brine $(10 \mathrm{~mL})$ and dried $\left(\mathrm{Na}_{2} \mathrm{SO}_{4}\right)$. Solvent was evaporated under reduced pressure and purified the residue by column chromatography (Silica gel, 60-120 mesh, 2\% EtOAc in pet. ether) to furnish 10 (7.35 g, 91.3\%) as a yellow liquid. [ $\alpha]_{D}-17.7$ (c 1.0, $\mathrm{CHCl}_{3}$ ); IR (neat): 3394, 2929.6, 1718, 1612, 1456, 1247, $823 \mathrm{~cm}^{-1} ;{ }^{1} \mathrm{H} \mathrm{NMR}\left(\mathrm{CDCl}_{3}, 300 \mathrm{MHz}\right) \delta$ (ppm): 7.27-7.24 $(\mathrm{m}, 5 \mathrm{H}), 7.21(\mathrm{~d}, J 8.3 \mathrm{~Hz}, 2 \mathrm{H}), 6.97(\mathrm{dd}, J 4.53,8.3 \mathrm{~Hz}, 2 \mathrm{H}), 5.92-5.76(\mathrm{~m}, 1 \mathrm{H}), 5.09-5.0(\mathrm{~m}, 2 \mathrm{H}), 4.60(\mathrm{~d}, J 11.3$ $\mathrm{Hz}, 1 \mathrm{H}), 4.53(\mathrm{~s}, 1 \mathrm{H}), 4.50(\mathrm{~d}, J 12.8 \mathrm{~Hz}, 1 \mathrm{H}), 4.39(\mathrm{~s}, 1 \mathrm{H}), 3.78(\mathrm{~s}, 3 \mathrm{H}), 3.76-3.71(\mathrm{~m}, 1 \mathrm{H}), 3.57(\mathrm{q}, J 5.28 \mathrm{~Hz}, 1 \mathrm{H})$, 3.52-3.43 (m, 2H), $2.37(\mathrm{t}, J 6.7 \mathrm{~Hz}, 2 \mathrm{H}), 0.89(\mathrm{~s}, 9 \mathrm{H}), 0.37(\mathrm{~s}, 6 \mathrm{H}) ;{ }^{13} \mathrm{C} \mathrm{NMR}\left(\mathrm{CDCl}_{3}, 150 \mathrm{MHz}\right) \delta(\mathrm{ppm}): 135.4$, $129.3,128.2,127.8,127.3,116.8,113.6,80.4,78.5,72.3,72.2,62.8,55.2,34.9,25.9$, -5.3. ESIMS: 479 (M+ $\mathrm{Na})^{+}, 457(\mathrm{M}+\mathrm{H})$.

(4S,5R)-4-(Benzyloxy)-6-[1-(tert.-butyl)-1,1-dimethylsilyl]oxy-5-[(4-methoxybenzyl)oxy]- hexane-1,2-diol (11). To the stirred solution of $10(6.85 \mathrm{~g}, 15.05 \mathrm{mmol})$ in acetone, water $(9: 1 ; 30 \mathrm{~mL}) \mathrm{NMO}(7.07 \mathrm{~mL}, 30.1$ $\mathrm{mmol}$ ) was added at room temperature followed by the addition of $\mathrm{OsO}_{4}(2 \mathrm{~mL})$ catalytic amount (which was covered by carbon paper). After $12 \mathrm{~h}$, reaction mixture was quenched with $\mathrm{NaHSO}_{3}(5 \mathrm{~g})$, acetone was removed and extracted the residue with ethyl acetate $(2 \times 50 \mathrm{~mL})$. The organic layers were washed with water $(2 \times 10 \mathrm{~mL})$, brine $(10 \mathrm{~mL})$, dried $\left(\mathrm{Na}_{2} \mathrm{SO}_{4}\right)$, evaporated and purified the residue by colomn chromatography (Silica gel, 60-120 mesh, 30\% EtOAc in pet. ether) to gave $11(4.6 \mathrm{~g}, 63 \%)$ as a liquid. $[\alpha]_{\mathrm{D}}{ }^{25}-32.9\left(\mathrm{c} 1.0, \mathrm{CHCl}_{3}\right)$; IR (neat): 3395, 2929, 2858, 1717, 1611, 1458, 1360, 1248, $824 \mathrm{~cm}^{-1} ;{ }^{1} \mathrm{H} \mathrm{NMR}\left(\mathrm{CDCl}_{3}\right) \delta$ (ppm): $7.31-7.25$ (m, $5 \mathrm{H}), 7.21(\mathrm{~d}, J 8.68 \mathrm{~Hz}, 2 \mathrm{H}), 6.82(\mathrm{~d}, J 8.68 \mathrm{~Hz}, 2 \mathrm{H}), 4.6-4.47(\mathrm{~m}, 4 \mathrm{H}), 3.85-3.78(\mathrm{~m}, 1 \mathrm{H}), 3.78(\mathrm{~s}, 3 \mathrm{H}), 3.72-3.6$ $(\mathrm{m}, 3 \mathrm{H}), 3.5-3.46(\mathrm{~m}, 1 \mathrm{H}), 3.4-3.32(\mathrm{~m}, 2 \mathrm{H}), 1.69-1.62(\mathrm{~m}, 2 \mathrm{H}), 0.88(\mathrm{~s}, 9 \mathrm{H}), 0.38(\mathrm{~s}, 6 \mathrm{H}) ;{ }^{13} \mathrm{C} \mathrm{NMR}\left(\mathrm{CDCl}_{3}, 150\right.$ $\mathrm{MHz}) \delta(\mathrm{ppm}): 128.4,128.1,127.8,113.7,79.7,78.9,72.4,69.3,66.8,62.5,55.2,32.9,25.8,-5.4$; ESIMS: 513 $(\mathrm{M}+\mathrm{Na})^{+}$.

(3S,4R)-3-(Benzyloxy)-5-[1-(tert.-butyl)-1,1-dimethylsilyl]oxy-4-[(4-methoxybenzyl) oxy]pentan-1-ol (13). To a cooled $\left(0^{\circ} \mathrm{C}\right)$ solution of $11(4.61 \mathrm{~g}, 9.42 \mathrm{mmol})$ in $\mathrm{CH}_{2} \mathrm{Cl}_{2}(20 \mathrm{~mL}), \mathrm{NalO}_{4}(3.02 \mathrm{~g}, 14.14 \mathrm{mmol})$ followed by 
sat. $\mathrm{NaHCO}_{3}(2 \mathrm{~mL})$ were added and stirred at room temperature for $5 \mathrm{~h}$. Reaction mixture was dried $\left(\mathrm{Na}_{2} \mathrm{SO}_{4}\right)$, filtered and evaporated under reduced pressure gave aldehyde 12, which was directly used as such for the next step.

To a cooled $\left(0^{\circ} \mathrm{C}\right)$ solution of $12(2.92 \mathrm{~g}, 6.37 \mathrm{mmol})$ in methanol $(20 \mathrm{~mL}), \mathrm{NaBH}_{4}(0.5 \mathrm{~g}, 12.75 \mathrm{mmol})$ was added portion wise for $30 \mathrm{~min}$ and stirred at room temperature for $5 \mathrm{~h}$. After that methanol was removed and extracted with ethyl acetate $(2 \times 30 \mathrm{~mL})$. The organic layers were washed with water $(2 \times 10 \mathrm{~mL})$, brine $(10$ $\mathrm{mL})$, dried $\left(\mathrm{Na}_{2} \mathrm{SO}_{4}\right)$, evaporated and purified the residue by column chromatography (Silica gel, 60-120 mesh, $20 \%$ EtOAc in pet. ether) to furnish $13(2.28 \mathrm{~g}, 76 \%)$ as a colorless liquid. [ $\alpha]_{\mathrm{D}}{ }^{25}-49.7\left(c \mathrm{c} .1, \mathrm{CHCl}_{3}\right)$; IR (neat):

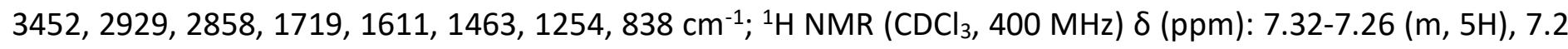
(d, J $8.42 \mathrm{~Hz}, 2 \mathrm{H}), 6.79(\mathrm{~d}, J 8.4 \mathrm{~Hz} 2 \mathrm{H}), 4.62(\mathrm{~d}, J 10.98 \mathrm{~Hz}, 1 \mathrm{H}), 4.59(\mathrm{~s}, 1 \mathrm{H}), 4.57(\mathrm{~s}, 1 \mathrm{H}), 4.49(\mathrm{~d}, J 11.35 \mathrm{~Hz}$, $1 \mathrm{H}), 3.78(\mathrm{~s}, 3 \mathrm{H}), 3.78-3.74(\mathrm{~m}, 1 \mathrm{H}), 3.71-3.6(\mathrm{~m}, 5 \mathrm{H}), 1.89-1.73(\mathrm{~m}, 2 \mathrm{H}), 0.89(\mathrm{~s}, 9 \mathrm{H}), 0.04(\mathrm{~s}, 6 \mathrm{H}) ;{ }^{13} \mathrm{C} \mathrm{NMR}$ $\left(\mathrm{CDCl}_{3}, 150 \mathrm{MHz}\right) \delta(\mathrm{ppm}):$ 129.4, 128.4, 127.9, 127.7, 113.6, 79.9, 77.9, 72.5, 71.9, 62.6, 60.2, 55.2, 32.3, 25.8, -5.4; ESIMS: $483(\mathrm{M}+\mathrm{Na})^{+}, 461(\mathrm{M}+\mathrm{H})$.

[(2R,3S)-3-(Benzyloxy)-2-[(4-methoxybenzyl)oxy]-5-(methoxymethoxy)pentyl]oxy(tert-butyl)dimethyl silane (14). To a cooled $\left(0^{\circ} \mathrm{C}\right.$ ) solution of $13(2.6 \mathrm{~g}, 5.65 \mathrm{mmol})$ in $\mathrm{CH}_{2} \mathrm{Cl}_{2}(15 \mathrm{~mL})$, DIPEA (5.87 mL, $\left.33.91 \mathrm{mmol}\right)$ and MOM-Cl $(0.91 \mathrm{~mL}, 11.3 \mathrm{mmol})$ were added sequentially and stirred at room temperature for $6 \mathrm{~h}$. The reaction mixture was evaporated and purified the residue by column chromatography (Silica gel, 60-120 mesh, 5\% EtOAc in pet. ether) to afford $14(2.57 \mathrm{~g}, 92 \%)$ as a yellow liquid. [ $\alpha]_{\mathrm{D}}{ }^{25}-27.1$ (c 0.6, $\mathrm{CHCl}_{3}$ ); IR (neat): 3446, 2929, 2858, 1720, 1609, 1460, 1101, $837 \mathrm{~cm}^{-1}$; ${ }^{1} \mathrm{H} \mathrm{NMR}\left(\mathrm{CDCl}_{3}, 500 \mathrm{MHz}\right) \delta(\mathrm{ppm}): 7.29-7.26(\mathrm{~m}, 5 \mathrm{H}), 7.2(\mathrm{~d}, J$ $8.78 \mathrm{~Hz}, 2 \mathrm{H}) .6 .79(\mathrm{~d}, J 8.78 \mathrm{~Hz}, 2 \mathrm{H}), 4.62-4.56(\mathrm{~m}, 3 \mathrm{H}), 4.52-4.45(\mathrm{~m}, 3 \mathrm{H}), 3.77(\mathrm{~s}, 3 \mathrm{H}), 3.73-3.67(\mathrm{~m}, 3 \mathrm{H}), 3.58$ $(\mathrm{t}, J 6.83 \mathrm{~Hz}, 3 \mathrm{H}), 3.28(\mathrm{~s}, 3 \mathrm{H}), 1.84-1.79(\mathrm{~m}, 2 \mathrm{H}), 0.89(\mathrm{~s}, 9 \mathrm{H}), 0.04(\mathrm{~s}, 6 \mathrm{H}) ;{ }^{13} \mathrm{C} \mathrm{NMR}\left(\mathrm{CDCl}_{3}, 150 \mathrm{MHz}\right) \delta(\mathrm{ppm})$ : $129.3,128.2,127.9,127.5,113.6,96.4,96.1,80.6,76.3,72.4,72.3,64.5,62.9,55.18,55.13,30.7,29.7,25.9,-$ 5.3; ESIMS: $527(\mathrm{M}+\mathrm{Na})^{+}, 522\left(\mathrm{M}+\mathrm{NH}_{4}\right)^{+}$.

(2R,3S)-3-(Benzyloxy)-2-[(4-methoxybenzyl)oxy]-5-(methoxymethoxy)pentan-1-ol (15). To a cooled (0 $\left.{ }^{\circ} \mathrm{C}\right)$ solution of $14(2.75 \mathrm{~g}, 5.45 \mathrm{mmol})$ in dry THF $(15 \mathrm{~mL})$ under nitrogen atmosphere, TBAF $(6.54 \mathrm{~mL}, 6.54 \mathrm{mmol})$ was added and stirred for $3 \mathrm{~h}$. After completion of reaction, reaction mixture was diluted with water $(5 \mathrm{~mL})$ and extracted with ethyl acetate $(2 \times 50 \mathrm{~mL})$. Organic layers were washed with water $(2 \times 10 \mathrm{~mL})$, brine $(10$ $\mathrm{mL}$ ), dried $\left(\mathrm{Na}_{2} \mathrm{SO}_{4}\right)$, evaporated and purified the residue by colomn chromatography (Silica gel, 60-120 mesh, $25 \%$ EtOAc in pet. ether) furnished $15(1.8 \mathrm{~g}, 85 \%)$ as a liquid. $[\alpha]_{\mathrm{D}}-15.4$ (c 1.0, $\left.\mathrm{CHCl}_{3}\right)$; IR (neat): 3451, 2929, 2857, 2102, 1722, 1612, 1514, 1360, 1041, $777 \mathrm{~cm}^{-1} ;{ }^{1} \mathrm{H} \mathrm{NMR}\left(\mathrm{CDCl}_{3}, 500 \mathrm{MHz}\right) \delta$ (ppm): 7.31-7.29 (m, 5H), $7.21(\mathrm{~d}, J 8.5 \mathrm{~Hz}, 2 \mathrm{H}), 6.81(\mathrm{~d}, J 8.3 \mathrm{~Hz}, 2 \mathrm{H}), 4.65$ (d, J $11.2 \mathrm{~Hz}, 1 \mathrm{H}), 4.62-4.49(\mathrm{~m}, 5 \mathrm{H}), 3.78(\mathrm{~s}, 3 \mathrm{H}), 3.77-3.73$ $(\mathrm{m}, 1 \mathrm{H}), 3.70-3.69(\mathrm{~m}, 2 \mathrm{H}), 3.60(\mathrm{t}, J 5.85 \mathrm{~Hz}, 2 \mathrm{H}), 3.50(\mathrm{q}, J 4.8 \mathrm{~Hz}, 1 \mathrm{H}), 3.30(\mathrm{~s}, 3 \mathrm{H}), 1.86-1.81(\mathrm{~m}, 2 \mathrm{H}) ;{ }^{13} \mathrm{C} \mathrm{NMR}$ $\left(\mathrm{CDCl}_{3}, 150 \mathrm{MHz}\right) \delta$ (ppm): 129.4, 128.3, 127.9, 127.7, 113.8, 96.4, 80.6, 76.4, 72.9, 71.8, 64.2, 61.3, 55.2, 31.5; ESIMS: $413(\mathrm{M}+\mathrm{Na})^{+}, 391(\mathrm{M}+\mathrm{H})$.

Methyl(E,4R,5S)-5-(benzyloxy)-4-[(4-methoxybenzyl)oxy]-7-(methoxymethoxy)-2-eptenoate (17). To a solution of oxalyl chloride (1.19 g, $9.42 \mathrm{mmol})$ in dry $\mathrm{CH}_{2} \mathrm{Cl}_{2}(5 \mathrm{~mL})$ at $-78{ }^{\circ} \mathrm{C}$, dry DMSO (1.46 g, $\left.18.84 \mathrm{mmol}\right)$ was added drop wise and stirred for $20 \mathrm{~min}$. A solution of $15(2.45 \mathrm{~g}, 6.28 \mathrm{mmol})$ in dry $\mathrm{CH}_{2} \mathrm{Cl}_{2}(10 \mathrm{~mL}) \mathrm{was}$ added and stirred for $2 \mathrm{~h}$ at $-78^{\circ} \mathrm{C}$. It was quenched with $\mathrm{Et}_{3} \mathrm{~N}(3.8 \mathrm{~g}, 37.69 \mathrm{mmol})$ and diluted with $\mathrm{CH}_{2} \mathrm{Cl}_{2}(30$ $\mathrm{mL})$. The reaction mixture was washed with water $(10 \mathrm{~mL})$, brine $(10 \mathrm{~mL})$, dried $\left(\mathrm{Na}_{2} \mathrm{SO}_{4}\right)$ and evaporated to furnish the corresponding aldehyde 16.

The aldehyde $16(2.43 \mathrm{~g}, 6.26 \mathrm{mmol})$ was dissolved in benzene $(30 \mathrm{~mL})$ and treated with (methoxycarbonylmethylene)triphenyl phosphorane $(2.51 \mathrm{~g}, 7.51 \mathrm{mmol})$ at reflux temperature. After $2 \mathrm{~h}$, solvent was evaporated and purified the residue by column chromatography (Silica gel, 60-120 mesh, 10\% 
EtOAc in pet. ether) to furnish 17 (E:Z/19:1) $(2.1 \mathrm{~g}, 75.5 \%)$ as a yellow liquid. $\mathbf{E}$ isomer: $[\alpha]_{D}-144.6$ (c 1.0, $\mathrm{CHCl}_{3}$ ); IR (neat): 3446, 2932, 1722, 1612, 1512, 1448, 1386, 1164, $1037 \mathrm{~cm}^{-1} ;{ }^{1} \mathrm{H} \mathrm{NMR}\left(\mathrm{CDCl}_{3}, 300 \mathrm{MHz}\right) \delta$ (ppm): 7.29-7.24 (m, 5H), $7.18(\mathrm{~d}, J 8.68 \mathrm{~Hz}, 2 \mathrm{H}), 6.90(\mathrm{dd},, J 6.04,12.3 \mathrm{~Hz}, 1 \mathrm{H}), 6.80(\mathrm{~d}, J 8.6 \mathrm{~Hz}, 2 \mathrm{H}), 6.04(\mathrm{~d}, J$ $15.5 \mathrm{~Hz}, 1 \mathrm{H}), 4.60(\mathrm{~d}, J 7.22 \mathrm{~Hz}, 1 \mathrm{H}), 4.58(\mathrm{~d}, J 10.2 \mathrm{~Hz}, 1 \mathrm{H}), 4.52-4.44(\mathrm{~m}, 3 \mathrm{H}), 4.37(\mathrm{~d}, J 11.7 \mathrm{~Hz}, 1 \mathrm{H}), 4.05-4.01$ $(\mathrm{m}, 1 \mathrm{H}), 3.78(\mathrm{~s}, 3 \mathrm{H}), 3.75(\mathrm{~s}, 3 \mathrm{H}), 3.72-3.65(\mathrm{~m}, 1 \mathrm{H}), 3.55(\mathrm{t}, J 5.6 \mathrm{~Hz}, 2 \mathrm{H}), 3.27(\mathrm{~s}, 3 \mathrm{H}), 1.76(\mathrm{q}, J 6.42 \mathrm{~Hz}, 2 \mathrm{H})$; ${ }^{13} \mathrm{C} \mathrm{NMR}\left(\mathrm{CDCl}_{3}, 150 \mathrm{MHz}\right) \delta$ (ppm): 145.6, 129.3, 128.3, 127.8, 127.6, 123.2, 113.7, 96.4, 79.6, 78.0, 72.9, 64.1, 55.2, 55.1, 51.6, 31.2; HRMS $\mathrm{m} / \mathrm{z}[\mathrm{M}+\mathrm{Na}]^{+}$found 467.2055; calculated 467.2045 for $\mathrm{C}_{25} \mathrm{H}_{32} \mathrm{O}_{7} \mathrm{Na}$. $\mathrm{Z}$ isomer: $[\alpha]_{D}$ -58.0 (c 1.2, $\mathrm{CHCl}_{3}$ ); IR (neat): 2939, 1721, 1649, 1612, 1513, 1447, 1299, 1196, $1041 \mathrm{~cm}^{-1},{ }^{1} \mathrm{H} \mathrm{NMR}_{\text {(CDCl }}, 300$ $\mathrm{MHz}) \delta(\mathrm{ppm}): 7.31-7.21(\mathrm{~m}, 5 \mathrm{H}), 7.18(\mathrm{~d}, J 8.68 \mathrm{~Hz}, 2 \mathrm{H}), 6.76(\mathrm{~d}, J 8.68 \mathrm{~Hz}, 2 \mathrm{H}), 6.26(\mathrm{dd}, J 8.68,11.07 \mathrm{~Hz}, 1 \mathrm{H})$, $5.91(\mathrm{~d}, J 11.7 \mathrm{~Hz}, 1 \mathrm{H}), 5.29(\mathrm{~d}, J 8.3 \mathrm{~Hz}, 1 \mathrm{H}), 4.73(\mathrm{~d}, J 11.7 \mathrm{~Hz}, 1 \mathrm{H}), 4.57-4.39(\mathrm{~m}, 6 \mathrm{H}), 3.77(\mathrm{~s}, 3 \mathrm{H}), 3.77-3.70$ $(\mathrm{m}, 2 \mathrm{H}), 3.70(\mathrm{~s}, 3 \mathrm{H}), 3.56-3.51(\mathrm{~m}, 2 \mathrm{H}), 3.25(\mathrm{~s}, 3 \mathrm{H}), 1.87-1.77(\mathrm{~m}, 1 \mathrm{H}), 1.72-1.64(\mathrm{~m}, 1 \mathrm{H})$; ESIMS: $462(\mathrm{M}+$ $\left.\mathrm{NH}_{4}\right)^{+}, 467(\mathrm{M}+\mathrm{Na})^{+}$.

$(E, 4 R, 5 S)$-5-(Benzyloxy)-4-[(4-methoxybenzyl)oxy]-7-(methoxymethoxy)-2-hepten-1-ol (18). To the suspension of lithium aluminium hydride $(\mathrm{LAH})(0.16 \mathrm{~g}, 4.22 \mathrm{mmol})$ in dry ether $(5 \mathrm{~mL})$ under nitrogen atmosphere at $0{ }^{\circ} \mathrm{C}, \mathrm{AlCl}_{3}(0.18 \mathrm{~g}, 1.40 \mathrm{mmol})$ in dry ether $(3 \mathrm{~mL})$ was added and stirred for $30 \mathrm{~min}$. A solution of $17 \mathrm{~b}(1.25 \mathrm{~g}, 2.81 \mathrm{mmol})$ in dry ether $(5 \mathrm{~mL})$ was added at the same temperature and stirred for an additional $1 \mathrm{~h}$. Reaction mixture was quenched with sat. $\mathrm{NH}_{4} \mathrm{Cl}(5 \mathrm{~mL})$ solution, filtered through sintered funnel, dried $\left(\mathrm{Na}_{2} \mathrm{SO}_{4}\right)$, evaporated and purified the residue by column chromatography (Silica gel, 60-120 mesh, 20\% EtOAc in pet. ether) to give 18 (1.0 g, 78\%) as a liquid. [ $\alpha]_{\mathrm{D}}{ }^{25}-82.2$ (c 1.0, $\mathrm{CHCl}_{3}$ ); IR (neat): 34450, 2929, 2855, 1460, $1032 \mathrm{~cm}^{-1} ;{ }^{1} \mathrm{H} \mathrm{NMR}\left(\mathrm{CDCl}_{3}, 300 \mathrm{MHz}\right) \delta(\mathrm{ppm}): 7.28-7.27(\mathrm{~m}, 5 \mathrm{H}), 7.21(\mathrm{~d}, J 8.7 \mathrm{~Hz}, 2 \mathrm{H}), 6.80$ (d, J $8.7 \mathrm{~Hz}, 2 \mathrm{H}), 5.82(\mathrm{tt}, J 4.9 \mathrm{~Hz}, 1 \mathrm{H}), 5.68(\mathrm{dd}, J$ 7.55, $13.4 \mathrm{~Hz}, 1 \mathrm{H}), 4.60(\mathrm{~d}, J 11.7 \mathrm{~Hz}, 1 \mathrm{H}), 4.50-4.46(\mathrm{~m}, 4 \mathrm{H})$, $4.33(\mathrm{~d}, J 11.7 \mathrm{~Hz}, 1 \mathrm{H}), 4.12(\mathrm{~d}, J 4.9 \mathrm{~Hz}, 2 \mathrm{H}), 3.80(\mathrm{~s}, 3 \mathrm{H}), 3.80(\mathrm{dd}, J 3.4,3.7 \mathrm{~Hz}, 1 \mathrm{H}), 3.7-3.64(\mathrm{~m}, 1 \mathrm{H}), 3.56(\mathrm{t}$, $2 \mathrm{H}), 3.30(\mathrm{~s}, 3 \mathrm{H}), 1.8-1.71(\mathrm{~m}, 2 \mathrm{H}) ;{ }^{13} \mathrm{C} \mathrm{NMR}\left(\mathrm{CDCl}_{3}, 150 \mathrm{MHz}\right) \delta(\mathrm{ppm}): 133.8,129.2,128.5,128.2,127.9,127.5$, 113.6, 96.4, 81.2, 78.3, 72.9, 70.0, 64.4, 62.9, 55.2, 31.4; HRMS $m / z[\mathrm{M}+\mathrm{Na}]^{+}$found 439.2103; calculated 439.2096 for $\mathrm{C}_{24} \mathrm{H}_{32} \mathrm{O}_{6} \mathrm{Na}$.

(2S,3R)-3-[(1S,2S)-2-(Benzyloxy)-1-[(4-methoxybenzyl)oxy]-4-(methoxymethoxy)butyl]- oxiran-2-yl methanol (3). To a stirred solution of (+)-DIPT $(0.12 \mathrm{~g}, 0.50 \mathrm{mmol})$ in $\mathrm{CH}_{2} \mathrm{Cl}_{2}(5 \mathrm{~mL})$ at $-20^{\circ} \mathrm{C}$ containing MS $4 \AA$ ( $\left.0.4 \mathrm{~g}\right)$, sequentially $\mathrm{Ti}\left(\mathrm{O}^{\prime} \mathrm{Pr}\right)_{4}(0.119 \mathrm{~g}, 0.42 \mathrm{mmol})$ and $t \mathrm{BHP}(0.14 \mathrm{~mL}, 0.42 \mathrm{mmol})$ were added and stirred for $20 \mathrm{~min}$. A solution of $18(0.35 \mathrm{~g}, 0.84 \mathrm{mmol})$ in $\mathrm{CH}_{2} \mathrm{Cl}_{2}(5 \mathrm{~mL})$ was added and stirred for $15 \mathrm{~h}$ at $-20{ }^{\circ} \mathrm{C}$. The reaction mixture was quenched with $10 \% \mathrm{NaOH}$ solution ( $0.5 \mathrm{~g}$ in $5 \mathrm{~mL}$ brine) and stirred for $3 \mathrm{~h}$ and filtered. The organic layers were dried $\left(\mathrm{Na}_{2} \mathrm{SO}_{4}\right)$, evaporated and the residue obtained was purified by column chromatography (Silica gel, 60-120 mesh, 30\% EtOAc in pet. ether) to afford 3 (0.25 g, 70\%) as a colorless liquid. [ $\alpha]_{\mathrm{D}}{ }^{25}-54.9$ (c 0.4, $\mathrm{CHCl}_{3}$ ); IR (neat): 3422, 3063, 2978, 2929, 2870, 1605, $1453 \mathrm{~cm}^{-1} ;{ }^{1} \mathrm{H} \mathrm{NMR} \mathrm{NCDCl}_{3}, 300$ $\mathrm{MHz}) \delta(\mathrm{ppm}): 7.28-7.26(\mathrm{~m}, 5 \mathrm{H}), 7.18(\mathrm{~d}, J 8.7 \mathrm{~Hz}, 2 \mathrm{H}), 6.8(\mathrm{~d}, J 8.3 \mathrm{~Hz}, 2 \mathrm{H}), 4.61(\mathrm{~d}, J 11.7 \mathrm{~Hz}, 1 \mathrm{H}), 4.53-4.47$ $(\mathrm{m}, 5 \mathrm{H}), 3.77(\mathrm{~s}, 3 \mathrm{H}), 3.72(\mathrm{~m}, 1 \mathrm{H}), 3.6-3.57(\mathrm{~m}, 3 \mathrm{H}), 3.53(\mathrm{~m}, 1 \mathrm{H}), 3.30(\mathrm{~s}, 3 \mathrm{H}), 3.07(\mathrm{~m}, 1 \mathrm{H}), 1.9-1.83(\mathrm{~m}, 1 \mathrm{H})$; ${ }^{13} \mathrm{C} \mathrm{NMR}\left(\mathrm{CDCl}_{3}, 150 \mathrm{MHz}\right) \delta$ (ppm): 129.2, 128.3, 127.9, 127.6, 113.7, 96.5, 78.0, 72.7, 72.5, 64.3, 61.4, 55.9, $55.2,54.7,31.0$; HRMS $m / z[\mathrm{M}+\mathrm{Na}]^{+}$found 455.2052; calculated 455.2045 for $\mathrm{C}_{24} \mathrm{H}_{32} \mathrm{O}_{7} \mathrm{Na}$.

4-[(4-Methoxy benzyl)oxy]-2-butyn-1-ol (19). To a cooled $\left({ }^{\circ}{ }^{\circ} \mathrm{C}\right)$ solution of 2-butyn-1,4-diol (9.0 g, 104.4 $\mathrm{mmol}$ ) in dry THF (200 mL), NaH (2.76 g, $114.9 \mathrm{mmol})$ and TBAl $(3.64 \mathrm{~g}, 10.44 \mathrm{mmol})$ were added, stirred for 30 min and treated with a solution of $\operatorname{MPM}-\mathrm{Br}(20.7 \mathrm{~g}, 104.9 \mathrm{mmol})$ in dry THF $(100 \mathrm{~mL})$ for $12 \mathrm{~h}$ at room temperature. The reaction mixture was quenched with sat. $\mathrm{NH}_{4} \mathrm{Cl}$ solution $(20 \mathrm{~mL})$ and extracted with ethyl

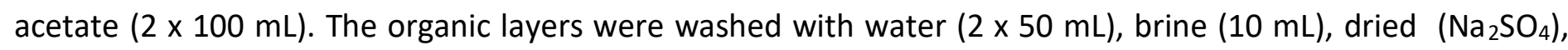
evaporated under reduced pressure and purified the residue by column chromatography (Silica gel, 60-120 
mesh, 25\% EtOAc in pet. ether) to furnish 19 (13.01 g, 62\%) as a yellow liquid. IR (neat): 3438, 2926, 2857, 2109, $1456 \mathrm{~cm}^{-1} ;{ }^{1} \mathrm{H}$ NMR $\left(\mathrm{CDCl}_{3}, 300 \mathrm{MHz}\right) \delta(\mathrm{ppm}): 7.20$ (d, J $\left.8.49 \mathrm{~Hz}, 2 \mathrm{H}\right), 6.82(\mathrm{~d}, J 8.49 \mathrm{~Hz}, 2 \mathrm{H}), 4.48(\mathrm{~s}, 2 \mathrm{H})$, 4.26-4.25 (m, 2H), 4.12-4.11 (m, 2H), $3.78(\mathrm{~s}, 3 \mathrm{H}), 2.09-2.03(\mathrm{~s}, 1 \mathrm{H})$; ESIMS: $229(\mathrm{M}+\mathrm{Na})^{+}, 224\left(\mathrm{M}+\mathrm{NH}_{4}\right)^{+}$.

(E)-4-[(4-Methoxybenzyl)oxy]-2-buten-1-ol (20). To a solution of 19 (6.5 g, $0.03 \mathrm{mmol}$ ) in dry ether (30 mL), $\mathrm{NaAlH}_{2}\left(\mathrm{OCH}_{2} \mathrm{CH}_{2} \mathrm{OMe}\right)_{2}\left(12.74 \mathrm{~mL}, 0.06 \mathrm{mmol}\right.$, solution in toulene) was added dropwise at $0{ }^{\circ} \mathrm{C}$ and stirred for $2 \mathrm{~h}$ at the same temperature. The reaction mixture was quenched with sat. $\mathrm{NH}_{4} \mathrm{Cl}$ solution $(8 \mathrm{~mL})$ and extracted with ethyl acetate $(2 \times 50 \mathrm{~mL})$. Organic layers were washed with water $(10 \mathrm{~mL})$, brine $(10 \mathrm{~mL})$, dried $\left(\mathrm{Na}_{2} \mathrm{SO}_{4}\right)$ and evaporated. The residue was purified by column chromatography (Silica gel, 60-120 mesh, 30\% EtOAc in pet. ether) afforded 20 (4.78 g, 73\%) as a light yellow liquid. IR (neat): 3453, 2929, 2859, 1611, 1512, 1458, 1301, $823 \mathrm{~cm}^{-1} ;{ }^{1} \mathrm{H} \mathrm{NMR}\left(\mathrm{CDCl}_{3}, 400 \mathrm{MHz}\right) \delta(\mathrm{ppm}): 7.21(\mathrm{~d}, J 8.85 \mathrm{~Hz}, 2 \mathrm{H}), 6.82(\mathrm{~d}, J 8.22 \mathrm{~Hz}, 2 \mathrm{H}), 5.86-$ $5.75(\mathrm{~m}, 1 \mathrm{H}), 4.48-4.41(\mathrm{~m}, 1 \mathrm{H}), 4.41(\mathrm{~s}, 2 \mathrm{H}), 4.10(\mathrm{~d}, J 5.06 \mathrm{~Hz}, 1 \mathrm{H}), 3.95(\mathrm{~d}, J 5.06 \mathrm{~Hz}, 1 \mathrm{H}), 3.78-3.66(\mathrm{~m}, 2 \mathrm{H})$, $3.78(\mathrm{~s}, 3 \mathrm{H})$; ESIMS: $231(\mathrm{M}+\mathrm{Na})^{+}, 226\left(\mathrm{M}+\mathrm{NH}_{4}\right)^{+}$.

((2S,3S)-3-[(4-Methoxybenzyl)oxy]methyloxiran-2-yl)methanol (21). To a stirred solution of (+)-DIPT (0.94 g, $4.03 \mathrm{mmol})$ in $\mathrm{CH}_{2} \mathrm{Cl}_{2}(10 \mathrm{~mL})$ at $-20^{\circ} \mathrm{C}$ containing MS $4 \AA$ ( $\left.0.4 \mathrm{~g}\right)$, sequentially $\mathrm{Ti}\left(\mathrm{O}^{i} \mathrm{Pr}\right){ }_{4}(1.14 \mathrm{~g}$, $4.03 \mathrm{mmol})$ and cumenehydroperoxide $(2.59 \mathrm{~g}, 16.82 \mathrm{mmol}$ ) were added and stirred for $20 \mathrm{~min}$. A solution of 20 (4.2 g, 20.19 $\mathrm{mmol})$ in $\mathrm{CH}_{2} \mathrm{Cl}_{2}(20 \mathrm{~mL})$ was added and stirred for an additional $6 \mathrm{~h}$ at $-20{ }^{\circ} \mathrm{C}$. The reaction mixture was worked up as described for 3 and the residue purified by column chromatography (Silica gel, 60-120 mesh, $30 \%$ EtOAc in pet. ether) to furnish 21 (3.12 g, 69\%) as a yellow liquid. $[\alpha]_{\mathrm{D}}{ }^{25}-31.1$ (c 0.75, $\left.\mathrm{CHCl}_{3}\right)$; IR (neat): 3454, 2932, 1513, 1248, 1036, $915 \mathrm{~cm}^{-1} ;{ }^{1} \mathrm{H} \mathrm{NMR}\left(\mathrm{CDCl}_{3}, 300 \mathrm{MHz}\right) \delta(\mathrm{ppm}): 7.19$ (d, J $\left.8.68 \mathrm{~Hz}, 2 \mathrm{H}\right), 6.80(\mathrm{~d}, J$ $8.68 \mathrm{~Hz}, 2 \mathrm{H}), 4.45(\mathrm{q}, J 11.70 \mathrm{~Hz}, 2 \mathrm{H}), 3.84(\mathrm{~d}, J 12.46 \mathrm{~Hz}, 1 \mathrm{H}), 3.78(\mathrm{~s}, 3 \mathrm{H}), 3.63(\mathrm{dd}, J 5.73,11.70 \mathrm{~Hz}, 1 \mathrm{H}), 3.62-$ $3.55(\mathrm{~m}, 1 \mathrm{H}), 3.46(\mathrm{dd}, J$ 7.4, $11.33 \mathrm{~Hz}, 1 \mathrm{H}), 3.16-3.12(\mathrm{~m}, 1 \mathrm{H}), 3.02-3.00(\mathrm{~m}, 1 \mathrm{H})$; ESIMS: $247(\mathrm{M}+\mathrm{Na})^{+}, 242(\mathrm{M}$ $\left.+\mathrm{NH}_{4}\right)^{+}$.

Methyl $(E, 4 R, 5 R)-5$-hydroxy-6-[(4-methoxybenzyl)oxy]-4-methyl-2-hexenoate(23). To a stirred solution of 6 (2.35 g, $8.45 \mathrm{mmol})$ in $\mathrm{CH}_{2} \mathrm{Cl}_{2}(100 \mathrm{~mL})$ under nitrogen atmosphere at $-40{ }^{\circ} \mathrm{C}, 3 \mathrm{M} \mathrm{Me} 3 \mathrm{Al}(42.3 \mathrm{~mL}, 84.5 \mathrm{mmol})$ solution was added. After $10 \mathrm{~min}$, water $(0.91 \mathrm{~mL}, 50.7 \mathrm{mmol})$ was added very slowly and stirred additionally at the same temperature for $2 \mathrm{~h}$. The reaction mixture was quenched with sat. $\mathrm{NH}_{4} \mathrm{Cl}(10 \mathrm{~mL})$ solution, filtered through sintered funnel, dried $\left(\mathrm{Na}_{2} \mathrm{SO}_{4}\right)$, evaporated under reduced pressure and purified the residue by colomn chromatography (Silica gel, 60-120 mesh, 12\% EtOAc in pet. ether) to give 23 (2.11 g, 85\%) as a liquid. $[\alpha]_{D}+50.8$ (c 3.65, $\mathrm{CHCl}_{3}$ ); IR (neat): 3446, 2932, 1723, 1611, 1514, 1452, 1387, 1164, 919, $756 \mathrm{~cm}^{-1} ;{ }^{1} \mathrm{H} \mathrm{NMR}$ $\left(\mathrm{CDCl}_{3}, 500 \mathrm{MHz}\right) \delta(\mathrm{ppm}): 7.19(\mathrm{~d}, J 8.78 \mathrm{~Hz}, 2 \mathrm{H}), 6.96(\mathrm{dd}, J 7.8,15.6 \mathrm{~Hz}, 1 \mathrm{H}), 6.82(\mathrm{~d}, 2 \mathrm{H}), 5.79(\mathrm{~d}, J 15.6 \mathrm{~Hz}$, $1 \mathrm{H}), 4.44(\mathrm{~s}, 2 \mathrm{H}), 3.79(\mathrm{~s}, 3 \mathrm{H}), 3.71(\mathrm{~s}, 3 \mathrm{H}), 3.69-3.66(\mathrm{~m}, 2 \mathrm{H}), 3.42(\mathrm{dd}, J 3.9,9.7 \mathrm{~Hz}, 1 \mathrm{H}), 3.31(\mathrm{dd}, J 6.83,8.78$ $\mathrm{Hz}, 2 \mathrm{H}), 2.45$ (q, J $6.83 \mathrm{~Hz}, 1 \mathrm{H}), 1.09$ (d, J $6.83 \mathrm{~Hz}, 3 \mathrm{H}) ;{ }^{13} \mathrm{C} \mathrm{NMR}\left(\mathrm{CDCl}_{3}, 150 \mathrm{MHz}\right) \delta$ (ppm): 150.4, 129.6, 129.3, 121.2, 113.6, 73.0, 71.9, 55.1, 51.3, 39.4, 15.6; HRMS $\mathrm{m} / \mathrm{z}[2 \mathrm{M}+\mathrm{Na}]^{+}$found 611.2752; calculated 611.2773 for $\mathrm{C}_{39} \mathrm{H}_{40} \mathrm{O}_{5} \mathrm{Na}$.

(E,4S,5R)-6-[(4-Methoxybenzyl)oxy]-4-methyl-2-hexene-1,5-diol (24). To a suspension of LAH (0.25 g, 6.63 $\mathrm{mmol})$ in dry ether $(3 \mathrm{~mL})$ under nitrogen atmosphere at $0{ }^{\circ} \mathrm{C}, \mathrm{AlCl}_{3}(0.29 \mathrm{~g}, 2.21 \mathrm{mmol})$ in dry ether $(3 \mathrm{~mL}) \mathrm{was}$ added and stirred for $30 \mathrm{~min}$. A solution of $23(1.3 \mathrm{~g}, 4.42 \mathrm{mmol})$ in dry ether $(5 \mathrm{~mL})$ was added at the same temperature and continued stirring for $1 \mathrm{~h}$. Reaction mixture was quenched with sat. $\mathrm{NH}_{4} \mathrm{Cl}$ solution $(5 \mathrm{~mL})$, filtered through sintered funnel, dried $\left(\mathrm{Na}_{2} \mathrm{SO}_{4}\right)$, evaporated and purified the residue by column chromatography (Silica gel, 60-120 mesh, 35\% EtOAc in pet. ether) gave $24(0.68 \mathrm{~g}, 58 \%)$ as a liquid. $[\alpha]_{D}+22.2$ (c 0.6, $\mathrm{CHCl}_{3}$ ); IR (neat): 3450, 2929, 1448, 922, $739 \mathrm{~cm}^{-1} ;{ }^{1} \mathrm{H} \mathrm{NMR}\left(\mathrm{CDCl}_{3}, 300 \mathrm{MHz}\right) \delta$ (ppm): 7.17 (d, J $9.06 \mathrm{~Hz}$, $2 \mathrm{H}), 6.83(\mathrm{~d}, J 8.3 \mathrm{~Hz}, 2 \mathrm{H}), 5.64-5.62(\mathrm{~m}, 2 \mathrm{H}), 4.43(\mathrm{~s}, 3 \mathrm{H}), 4.03(\mathrm{~d}, J 3.77 \mathrm{~Hz}, 2 \mathrm{H}), 3.79(\mathrm{~s}, 3 \mathrm{H}), 3.59-3.54(\mathrm{~m}, 1 \mathrm{H})$, $3.42(\mathrm{dd}, J 3.02,9.06 \mathrm{~Hz}, 1 \mathrm{H}), 3.37-3.27(\mathrm{~m}, 1 \mathrm{H}), 2.34-2.25(\mathrm{~m}, 1 \mathrm{H}), 0.99(\mathrm{~d}, J 7.55 \mathrm{~Hz}, 3 \mathrm{H}) ;{ }^{13} \mathrm{C} \mathrm{NMR}\left(\mathrm{CDCl}_{3}, 150\right.$ 
$\mathrm{MHz} \delta(\mathrm{ppm}): 133.9,130.05,129.3,113.8,73.7,72.9,72.2,63.4,63.4,55.2,39.3,16.6 ; \mathrm{HRMS} \mathrm{m} / z$ [M+Na] $^{+}$ found 289.1429; calculated 289.1415 for $\mathrm{C}_{15} \mathrm{H}_{22} \mathrm{O}_{4} \mathrm{Na}$.

Methyl (E)-3-((2S,3S)-3-[(4-methoxybenzyl)oxy]methyloxiran-2-yl)-2-propenoate (6). To a solution of oxalyl chloride $(2.61 \mathrm{~g}, 20.75 \mathrm{mmol})$ in dry $\mathrm{CH}_{2} \mathrm{Cl}_{2}(10 \mathrm{~mL})$ at $-78{ }^{\circ} \mathrm{C}$, dry DMSO $(3.23 \mathrm{~mL}, 41.51 \mathrm{mmol})$ was added dropwise and stirred for $20 \mathrm{~min}$. A solution of $21(3.1 \mathrm{~g}, 13.83 \mathrm{mmol})$ in dry $\mathrm{CH}_{2} \mathrm{Cl}_{2}(15 \mathrm{~mL})$ was added and stirred for $2 \mathrm{~h}$ at $-78{ }^{\circ} \mathrm{C}$. It was quenched with $\mathrm{Et}_{3} \mathrm{~N}(8.38 \mathrm{~g}, 83.03 \mathrm{mmol})$ and diluted with $\mathrm{CH}_{2} \mathrm{Cl}_{2}(30 \mathrm{~mL})$. The reaction mixture was washed with water $(10 \mathrm{~mL})$, brine $(10 \mathrm{~mL})$, dried $\left(\mathrm{Na}_{2} \mathrm{SO}_{4}\right)$ and evaporated to furnish the corresponding aldehyde 22.

The aldehyde $22(3.0 \mathrm{~g}, 13.51 \mathrm{mmol})$ was dissolved in benzene $(40 \mathrm{~mL})$ and treated with (methoxycarbonylmethylene)triphenyl phosphorane $(5.41 \mathrm{~g}, 16.21 \mathrm{mmol}$ ) at reflux temperature. After $2 \mathrm{~h}$, solvent was evaporated and purified the residue by column chromatography (Silica gel, 60-120 mesh, 10\% EtOAc in pet. ether) to furnish $6(E: Z / 9: 1)(2.71 \mathrm{~g}, 72 \%)$ as a yellow liquid. $E$-isomer: $[\alpha]_{D}-21.5\left(c 0.45, \mathrm{CHCl}_{3}\right)$; IR (neat): 3480, 2926, 2854, 1721, 1654, 1513, 1460, 1252, $938 \mathrm{~cm}^{-1} ;{ }^{1} \mathrm{H} \mathrm{NMR}\left(\mathrm{CDCl}_{3}, 300 \mathrm{MHz}\right) \delta$ (ppm): 7.18 (d, J $8.3 \mathrm{~Hz}, 2 \mathrm{H}), 6.83(\mathrm{~d}, J 8.6 \mathrm{~Hz}, 2 \mathrm{H}), 6.65(\mathrm{dd}, J 7.17,15.86 \mathrm{~Hz}, 1 \mathrm{H}), 6.10$ (d, J $15.8 \mathrm{~Hz}, 1 \mathrm{H}), 4.51-4.42(\mathrm{~m}, 2 \mathrm{H})$, $3.79(\mathrm{~s}, 3 \mathrm{H}), 3.73(\mathrm{~s}, 3 \mathrm{H}), 3.65(\mathrm{dd}, J 3.39,11.33 \mathrm{~Hz}, 1 \mathrm{H}), 3.53(\mathrm{dd}, J 4.53,11.3 \mathrm{~Hz}, 1 \mathrm{H}), 3.46(\mathrm{~d}, J 6.79 \mathrm{~Hz}, 1 \mathrm{H})$, 3.06 (br s, $1 \mathrm{H}) ;{ }^{13} \mathrm{C} \mathrm{NMR}\left(\mathrm{CDCl}_{3}, 150 \mathrm{MHz}\right) \delta$ (ppm): 144.0, 129.4, 123.7, 113.8, 73.09, 68.7, 59.5, 55.2, 53.6, 51.7; ESIMS: $301(\mathrm{M}+\mathrm{Na})^{+}, 296\left(\mathrm{M}+\mathrm{NH}_{4}\right)^{+}, 579(2 \mathrm{M}+\mathrm{Na})^{+}$. Z-isomer: $[\alpha]_{\mathrm{D}}+115.3\left(\mathrm{c} \mathrm{1.0}, \mathrm{CHCl}_{3}\right)$; IR (neat): 3033, 2932, 2889, 1725, $1664 \mathrm{~cm}^{-1} ;{ }^{1} \mathrm{H} \mathrm{NMR}\left(\mathrm{CDCl}_{3}, 300 \mathrm{MHz}\right) \delta(\mathrm{ppm}): 7.23(\mathrm{~d}, J 8.87 \mathrm{~Hz}, 2 \mathrm{H}), 6.81(\mathrm{~d}, J 8.68$ $\mathrm{Hz}, 2 \mathrm{H}), 5.96(\mathrm{~d}, J 11.52 \mathrm{~Hz}, 1 \mathrm{H}), 5.78(\mathrm{dd}, J 8.12,11.52 \mathrm{~Hz}, 1 \mathrm{H}), 4.50(\mathrm{q}, J 11.7 \mathrm{~Hz}, 2 \mathrm{H}), 4.40-4.37(\mathrm{~m}, 1 \mathrm{H}), 3.75-$ $3.73(\mathrm{~m}, 1 \mathrm{H}), 3.73(\mathrm{~s}, 3 \mathrm{H}), 3.45(\mathrm{dd}, J 5.85,11.7 \mathrm{~Hz}, 1 \mathrm{H}), 3.08-3.04(\mathrm{~m}, 1 \mathrm{H})$; ESIMS: $301(\mathrm{M}+\mathrm{Na})^{+}, 296(\mathrm{M}+$ $\left.\mathrm{NH}_{4}\right)^{+}$.

(2R,3R,4E)-6-[1-(tert.-Butyl)-1,1-dimethylsilyl]oxy-1-[(4-methoxybenzyl)oxy]-3-methyl-4-hexen-2-ol (25). To a cooled $\left(0^{\circ} \mathrm{C}\right)$ solution of $24(0.8 \mathrm{~g}, 3.0 \mathrm{mmol})$ in $\mathrm{CH}_{2} \mathrm{Cl}_{2}(15 \mathrm{~mL})$, imidazole $(0.41 \mathrm{~g}, 6.0 \mathrm{mmol})$ was added. After $30 \mathrm{~min}$, TBS-Cl $(0.45 \mathrm{~g}, 3.0 \mathrm{mmol})$ was added portionwise for $30 \mathrm{~min}$ and stirred at room temperature for $2 \mathrm{~h}$. The reaction mixture was evaporated and purified the residue by column chromatography (Silica gel, 60120 mesh, $10 \%$ EtOAc in pet. ether) to afford $25(0.9 \mathrm{~g}, 82 \%)$ as a colorless liquid. $[\alpha]_{D}+3.62\left(c 0.4, \mathrm{CHCl}_{3}\right) ; \mathrm{IR}$ (neat): 3033, 2929, 2855, 1460, $1032 \mathrm{~cm}^{-1} ;{ }^{1} \mathrm{H} \mathrm{NMR}\left(\mathrm{CDCl}_{3}, 500 \mathrm{MHz}\right) \delta(\mathrm{ppm}): 7.2$ (d, J $\left.7.8 \mathrm{~Hz}, 2 \mathrm{H}\right), 6.8(\mathrm{~d}, J 8.3$ $\mathrm{Hz}, 2 \mathrm{H}), 5.61(\mathrm{dd}, J 7.8,15.6 \mathrm{~Hz}, 1 \mathrm{H}), 5.52(\mathrm{tt}, J 4.87 \mathrm{~Hz}, 1 \mathrm{H}), 4.44(\mathrm{~s}, 2 \mathrm{H}), 4.10(\mathrm{~d}, J 4.87 \mathrm{~Hz}, 2 \mathrm{H}), 3.79(\mathrm{~s}, 3 \mathrm{H})$, 3.59-3.57 (br s, 1H), 3.43 (dd, J $2.92 \mathrm{~Hz}, 10.7 \mathrm{~Hz}, 1 \mathrm{H}), 3.33-3.30(\mathrm{~m}, 1 \mathrm{H}), 2.33-2.29(\mathrm{~m}, 1 \mathrm{H}),, 1.01(\mathrm{~d}, J 6.83 \mathrm{~Hz}$, $3 \mathrm{H}), 0.89$ (s, 9H), $0.04(\mathrm{~s}, 6 \mathrm{H}) ;{ }^{13} \mathrm{C} \mathrm{NMR}\left(\mathrm{CDCl}_{3}, 150 \mathrm{MHz}\right) \delta$ (ppm): 133.9, 130.0, 129.3, 113.7, 73.7, 72.9, 72.2, 63.3, 55.2, 39.2, 16.6; ESIMS: $403(\mathrm{M}+\mathrm{Na})^{+}, 381(\mathrm{M}+\mathrm{H})$.

((E,4R,5R)-5-(Benzyloxy)-6-[(4-methoxybenzyl)oxy]-4-methyl-2-hexenyloxy)(tert.-buyl)-dimethylsilane (26). To a cooled $\left(0{ }^{\circ} \mathrm{C}\right)$ solution of $25(0.5 \mathrm{~g}, 1.31 \mathrm{mmol})$ in dry THF $(5 \mathrm{~mL}), \mathrm{NaH}(0.19 \mathrm{~g}, 7.89 \mathrm{mmol})$ was added, stirred for $30 \mathrm{~min}$ and treated with benzyl bromide $(0.27 \mathrm{~g}, 1.57 \mathrm{mmol})$ at room temperature for $6 \mathrm{~h}$. The reaction mixture was quenched with sat. $\mathrm{NH}_{4} \mathrm{Cl}$ solution $(5 \mathrm{~mL})$ and extracted with ethyl acetate $(2 \times 20 \mathrm{~mL})$. The organic layers were washed with water $(2 \times 10 \mathrm{~mL})$, brine $(10 \mathrm{~mL})$, dried $\left(\mathrm{Na}_{2} \mathrm{SO}_{4}\right)$, evaporated under reduced pressure and purified the residue by column chromatography (Silica gel, 60-120 mesh, 5\% EtOAc in pet. ether) to furnish $26(0.50 \mathrm{~g}, 82 \%)$ as a yellow liquid. [ $\alpha]_{\mathrm{D}}-21.1$ (c 0.4, $\left.\mathrm{CHCl}_{3}\right)$; IR (neat): 2985, 2929, 2863, 1613, $1512 \mathrm{~cm}^{-1} ;{ }^{1} \mathrm{H}$ NMR $\left(\mathrm{CDCl}_{3}, 500 \mathrm{MHz}\right) \delta(\mathrm{ppm}): 7.27-7.26(\mathrm{~m}, 5 \mathrm{H}) 7.19(\mathrm{~d}, J 8.3 \mathrm{~Hz}, 2 \mathrm{H}), 6.8(\mathrm{~d}, J 8.3 \mathrm{~Hz}$, $2 \mathrm{H}), 5.5-5.45(\mathrm{dd}, J$ 8.7, $15.6 \mathrm{~Hz}, 1 \mathrm{H}), 5.5-5.45(\mathrm{~m}, 1 \mathrm{H}), 4.68(\mathrm{~d}, J 11.07 \mathrm{~Hz}, 1 \mathrm{H}), 4.50(\mathrm{~d}, J 11.7 \mathrm{~Hz}, 1 \mathrm{H}), 4.40(\mathrm{~s}$, $2 \mathrm{H}), 4.07(\mathrm{~d}, J 4.87 \mathrm{~Hz}, 2 \mathrm{H}), 3.78(\mathrm{~s}, 3 \mathrm{H}), 3.55-3.43(\mathrm{~m}, 3 \mathrm{H}), 2.48-2.43(\mathrm{~m}, 1 \mathrm{H}), 1.02(\mathrm{~d}, J 6.8 \mathrm{~Hz}, 3 \mathrm{H}), 0.88(\mathrm{~s}, 9 \mathrm{H})$, $0.03(\mathrm{~s}, 6 \mathrm{H}) ;{ }^{13} \mathrm{C} \mathrm{NMR}\left(\mathrm{CDCl}_{3}, 150 \mathrm{MHz}\right) \delta$ (ppm): 129.2, 128.1, 127.7, 127.6, 113.7, 81.9, 72.9, 71.2, 64.0, 55.2, 38.6, 25.9,16.4, -5.07; ESIMS: $493(\mathrm{M}+\mathrm{Na})^{+}, 488\left(\mathrm{M}+\mathrm{NH}_{4}\right)^{+}$. 
(2R,3R,4E)-6-[1-(tert-Butyl)-1,1-dimethylsilyl]oxy-3-methyl-4-hexene-1,2-diol (27). To a solution of 25 (0.13 g, $0.35 \mathrm{mmol})$ in aq. $\mathrm{CH}_{2} \mathrm{Cl}_{2}(2 \mathrm{~mL}, 19: 1)$, DDQ $(0.12 \mathrm{~g}, 0.53 \mathrm{mmol})$ was added and stirred at room temperature for $1 \mathrm{~h}$. The reaction mixture was quenched with sat. $\mathrm{NaHCO}_{3}$ solution $(1 \mathrm{~mL})$, filtered and washed with $\mathrm{CH}_{2} \mathrm{Cl}_{2}$ $(10 \mathrm{~mL})$. The filtrate was washed with water $(3 \mathrm{~mL})$, brine $(3 \mathrm{~mL})$, dried $\left(\mathrm{Na}_{2} \mathrm{SO}_{4}\right)$ and evaporated under reduced pressure. The residue was purified by column chromatography (Silica gel, 60-120 mesh, 30\% EtOAc in pet. ether) to furnish 27 (0.06 g, 74\%) as a yellow liquid. [ $\alpha]_{D}+13.2$ (c 0.15, $\mathrm{CHCl}_{3}$ ); IR (neat): 3442, 2922, 2853, 1630, 1126, $835 \mathrm{~cm}^{-1}$; ${ }^{1} \mathrm{H} \mathrm{NMR}\left(\mathrm{CDCl}_{3}, 300 \mathrm{MHz}\right) \delta(\mathrm{ppm}): 5.64-5.52(\mathrm{~m}, 2 \mathrm{H}), 4.1$ (d, J $\left.5.3 \mathrm{~Hz}, 2 \mathrm{H}\right), 3.67-3.50(\mathrm{~m}$, $2 \mathrm{H}), 3.40-3.38(\mathrm{~m}, 1 \mathrm{H}), 2.51-2.44(\mathrm{~m}, 1 \mathrm{H}), 1.02(\mathrm{~d}, J 6.79 \mathrm{~Hz}, 3 \mathrm{H}), 0.90(\mathrm{~s}, 9 \mathrm{H}), 0.04(\mathrm{~s}, 6 \mathrm{H})$; ESIMS: $283(\mathrm{M}+$ $\mathrm{Na})^{+}$.

(4R)-4-((1R,2E)-4-[1-(tert-Butyl)-1,1-dimethylsilyl]oxy-1-methyl-2-butenyl)-2,2-dimethyl-1,3- dioxolane (28). A solution of $27(0.06 \mathrm{~g}, 0.002 \mathrm{mmol})$ in $\mathrm{CH}_{2} \mathrm{Cl}_{2}(2 \mathrm{~mL})$ was treated with 2,2-dimethoxypropane $(0.05 \mathrm{~g}, 0.005$ $\mathrm{mmol}$ ) and stirred in presence of PPTS (cat.) at room temperature for $3 \mathrm{~h}$. The reaction mixture was evaporated under reduced pressure and purified the residue by column chromatography (Silica gel, 60-120 mesh, 5\% EtOAc in pet. ether) to furnish $28(0.05 \mathrm{~g}, 73 \%)$ as a yellow liquid. $[\alpha]_{\mathrm{D}}+18.5\left(\mathrm{c} 0.2, \mathrm{CHCl}_{3}\right)$; IR (neat): 3067, 2931, 2857, $1456 \mathrm{~cm}^{-1} ;{ }^{1} \mathrm{H}$ NMR $\left(\mathrm{CDCl}_{3}, 300 \mathrm{MHz}\right) \delta(\mathrm{ppm}): 5.65-5.48(\mathrm{~m}, 2 \mathrm{H}), 4.12(\mathrm{~d}, J 4.53 \mathrm{~Hz}, 2 \mathrm{H})$, 3.94-3.87 (m, 2H), $3.56(\mathrm{t}, J 10.19 \mathrm{~Hz}, 1 \mathrm{H}), 2.35-2.26(\mathrm{~m}, 1 \mathrm{H}), 1.25(\mathrm{~s}, 6 \mathrm{H}), 1.01(\mathrm{~d}, J 6.7 \mathrm{~Hz}, 3 \mathrm{H}), 0.89(\mathrm{~s}, 9 \mathrm{H})$, $0.04(\mathrm{~s}, 6 \mathrm{H})$; ESIMS: $323(\mathrm{M}+\mathrm{Na})^{+}, 318\left(\mathrm{M}+\mathrm{NH}_{4}\right)^{+}$.

$(E, 4 R, 5 R)$-5-(Benzyloxy)-6-[(4-methoxy benzyl)oxy]-4-methyl-2-hexen-1-ol (29). To a cooled $\left(0^{\circ} \mathrm{C}\right)$ solution of $26(0.35 \mathrm{~g}, 0.77 \mathrm{mmol})$ in dry THF $(3 \mathrm{~mL})$ under nitrogen atmosphere, TBAF $(0.77 \mathrm{~mL}, 0.77 \mathrm{mmol})$ was added and stirred for $3 \mathrm{~h}$. The reaction mixture was diluted with water $(10 \mathrm{~mL})$ and extracted with ethyl acetate $(2 \mathrm{x}$ $50 \mathrm{~mL})$. Organic layers were washed with water $(2 \times 5 \mathrm{~mL})$, brine $(5 \mathrm{~mL})$, dried $\left(\mathrm{Na}_{2} \mathrm{SO}_{4}\right)$ and purified by column chromatography (60-120 Silica gel, 25\% EtOAc in pet. ether) to afford $29(0.23 \mathrm{~g}, 88 \%)$ as a liquid. $[\alpha]_{D}+11.2(c$

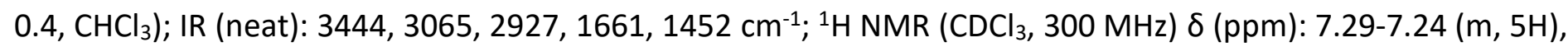
$7.17(\mathrm{~d}, J 8.30 \mathrm{~Hz}, 2 \mathrm{H}), 6.83(\mathrm{~d}, J 8.68 \mathrm{~Hz}, 2 \mathrm{H}), 5.67-5.50(\mathrm{~m}, 2 \mathrm{H}), 4.61(\mathrm{q}, J 11.70 \mathrm{~Hz}, 2 \mathrm{H}), 4.39(\mathrm{q}, J 11.70 \mathrm{~Hz}$, $2 \mathrm{H}), 4.00(\mathrm{~d}, J 4.53 \mathrm{~Hz}, 2 \mathrm{H}), 3.79(\mathrm{~s}, 3 \mathrm{H}), 3.48-3.41(\mathrm{~m}, 3 \mathrm{H}), 2.49-2.43(\mathrm{~m}, 1 \mathrm{H}), 1.03(\mathrm{~d}, J 6.79 \mathrm{~Hz}, 3 \mathrm{H})$; ESIMS: $379(\mathrm{M}+\mathrm{Na})^{+}, 374\left(\mathrm{M}+\mathrm{NH}_{4}\right)^{+}$.

4(E,4R,5R)-5-(Benzyloxy)-1-chloro-6-[(4-methoxybenzyl)oxy]-4-methyl-2-hexene (4). To a stirred solution of $29(0.11 \mathrm{~g}, 0.32 \mathrm{mmol})$ in $\mathrm{CCl}_{4}(2 \mathrm{~mL}), \mathrm{Ph}_{3} \mathrm{P}(0.17 \mathrm{~g}, 0.65 \mathrm{mmol})$ and $\mathrm{NaHCO}_{3}$ (cat.) were added and heated at reflux for $3 \mathrm{~h}$. The reaction mixture was evaporated and purified the residue by column chromatography (Silica gel, 60-120 mesh, 5\% EtOAc in pet. ether) to afford $4(0.11 \mathrm{~g}, 90 \%)$ as a liquid. $[\alpha]_{D}+24.3\left(c 0.33, \mathrm{CHCl}_{3}\right)$; IR (neat): $3063,2928,2864,1606,1451 \mathrm{~cm}^{-1} ;{ }^{1} \mathrm{H} \mathrm{NMR}\left(\mathrm{CDCl}_{3}, 300 \mathrm{MHz}\right) \delta(\mathrm{ppm}): 7.31-7.26(\mathrm{~m}, 5 \mathrm{H}), 7.21$ (d, J 8.30 $\mathrm{Hz}, 2 \mathrm{H}), 6.80(\mathrm{~d}, J 8.30 \mathrm{~Hz}, 2 \mathrm{H}), 4.56(\mathrm{q}, J 12.08 \mathrm{~Hz}, 2 \mathrm{H}), 4.42(\mathrm{~s}, 2 \mathrm{H}), 3.88-3.85(\mathrm{~m}, 2 \mathrm{H}), 3.79(\mathrm{~s}, 3 \mathrm{H}), 3.52-3.50$ $(\mathrm{m}, 1 \mathrm{H}), 3.37-3.26(\mathrm{~m}, 2 \mathrm{H}), 1.82-1.68(\mathrm{~m}, 1 \mathrm{H}), 0.89(\mathrm{~d}, J 6.79 \mathrm{~Hz}, 3 \mathrm{H})$; ESIMS: $397(\mathrm{M}+\mathrm{Na})^{+}, 392\left(\mathrm{M}+\mathrm{NH}_{4}\right)^{+}$.

\section{Acknowledgements}

The authors BSB and TP are thankful to UGC, New Delhi, India, for the award of research fellowships.

\section{References}


1. Sutherland, R.; Boon, R. J.; Griffin, K. E.; Masters, P. J.; Slocombe, B.; White, A. R. Antimicrob. Agents Chemother. 1985, 27, 495.

https://doi.org/10.1128/AAC.27.4.495

2. Badder, A.; Garre, C. Corresp.BI. Sweiz. Aertze 1887, 17, 385.

3. Gao, S.; Hothersall, J.; Murphy, J.; Wu, A. C.; Song, Z.; Stephens, E. R.; Thomas, C. M.; Crump, M. P.; Cox, R. J.; Simpson, T. J.; Willis C. L. J. Am. Chem. Soc. 2014, 136, 5501.

https://doi.org/10.1021/ja501731p

4. Fuller, A. T.; Mellows, G.; Woolford, M.; Banks, G. T.; Barrow, K. D.; Chain, E. B. Nature 1971, $234,416$. https://doi.org/10.1038/234416a0

5. Chain, E. B.; Mellows, G. J. Chem. Soc., Perkin Trans. 1 1977, 318. https://doi.org/10.1039/p19770000318

6. Alexander, R. G.; Clayton, J. P.; Luk, K.; Rogers, N. H.; King, T. J. J. Chem. Soc., Perkin Trans. $11978,561$. https://doi.org/10.1039/p19780000561

7. Hughes, J.; Mellows, G. Biochem. J. 1978, 176, 305. https://doi.org/10.1042/bj1760305

8. Boyce, J. M. J. Hosp. Infect. 2001, 48 (Suppl. A), S9. https://doi.org/10.1016/S0195-6701(01)90005-2

9. Marion, O.; Gao, X.; Marcus, S.; Hall, D. G. Bioorg. Med. Chem. 2009, 17, 1006. https://doi.org/10.1016/i.bmc.2008.01.001

10. Scott, R. W.; Mazzetti, C.; Simpson, T. J.; Willis, C. L. Chem. Commun. 2012, 48, 2639. https://doi.org/10.1039/c2cc17721h

11. Mckay, C.; Simpson, T. J.; Willis, C. L.; Forrest, A. K.; O’Hanlon, P. J. Chem. Commun. 2000, 1109.

12. Udawant, S. P.; Chakraborty, T. K. J. Org. Chem. 2011, 76, 6331. https://doi.org/10.1021/jo200396q

13. Wu, J.; Hothersall, J.; Mazzetti, C.; O’Con nell, Y.; Shields, J. A.; Rahman, A. S.; Cox, R. J.; Crosby, J.; Simpson, T. J.; Thomas, C. M. and Willis, C. L. Chem-BioChem 2008, 9, 1500.

https://doi.org/10.1002/cbic.200800085

14. Zhao, C.; Yuan, Z.; Y. Zhang, B. Ma, H. Li, S. Tang, X. Xie, X. She, Org. Chem. Front. 2014, 1, 105. https://doi.org/10.1039/C3Q000038A

15. Sandip, S.; Taebo, S. Eur. J. Org. Chem. 2014, 5063.

16. Chattopadhyay, A.; Mamdapur V. R. J. Org. Chem. 1995, 60, 585. https://doi.org/10.1021/jo00108a020

17. Jacobsen, E. N., Markd, I., Mungall, W. S., Schrcider, G. and K. Barry Sharpless; J. Am, Chem. Soc. 1988, 110, 1968.

https://doi.org/10.1021/ja00214a053

18. Mancuso, A. J.; Brownfain, D. S.; Swern, D. J. Org. Chem. 1979, 44, 4148. https://doi.org/10.1021/jo01337a028

19. For reviews on the Swern oxidation, see: i) Tidwell, T. T. Synthesis 1990, 857. ii) Tidwell, T. T. Org. React. 1990, 39, 297.

20. El-Batta, A.; Jiang, C.; Zhao, W.; Anness, R.; Cooksy, A. L.; Bergdahl, M. J. Org.Chem. 2007, $72,5244$. https://doi.org/10.1021/jo070665k

21. Sharma, G. V. M.; Shoban Babu, B.; Ramakrishna, K. V. S.; Nagendar, P.; Kunwar, A. C.; Schramm, P.; Baldauf, C.; Hofmann, H. J. Chem. Eur. J. 2009, 15, 5552 
https://doi.org/10.1002/chem.200802078

22. Sharma, G. V. M.; Shoban Babu, B.; Chatterjee, D.; Ramakrishna, K. V. S.; Kunwar, A. C.; Schramm, P.; Baldauf, C.; Hofmann, H. J. J. Org. Chem. 2009, 74, 6703.

https://doi.org/10.1021/jo901277a

23. Katsuki. T.; Sharpless, K. B. J. Am. Chem. Soc. 1980, 102, 5974. https://doi.org/10.1021/ja00538a077

24. Miyashita, M.; Hoshino, M.; Yoshikoshi, A. J. Org. Chem. 1991, 56, 6483. https://doi.org/10.1021/jo00023a001

25. Beau, J. M.; Aburaki, S.; Pougny, J. R.; Sinay, P. J. Am. Chem. Soc. 1983, 105, 621. https://doi.org/10.1021/ja00341a052

26. Soulie, J.; Ta, C.; Lallemand, J-Y. Tetrahedron 1992, 48, 443. https://doi.org/10.1016/S0040-4020(01)89006-2 